\title{
Linkages between Extreme Precipitation Events in the Central and Eastern United States and Rossby Wave Breaking
}

\author{
BENJAMIN J. MOORE \\ NOAA/Earth System Research Laboratory/Physical Sciences Division, Boulder, Colorado \\ DANIEL KEYSER AND LANCE F. BOSART \\ Department of Atmospheric and Environmental Sciences, University at Albany, State University of New York, \\ Albany, New York
}

(Manuscript received 22 February 2019, in final form 21 June 2019)

\begin{abstract}
Linkages between extreme precipitation events (EPEs) in the central and eastern United States and synoptic-scale Rossby wave breaking are investigated using 1979-2015 climatologies of EPEs and upper-level potential vorticity (PV) streamers. The investigation focuses on two domains over the central and eastern United States, respectively, and emphasizes widespread EPEs, events exhibiting exceptionally large precipitation volumes. The relative frequency of PV streamers is found to be significantly enhanced relative to climatology immediately upstream of each domain during widespread EPEs. Majorities of the widespread EPEs in the central $(\sim 79 \%)$ and eastern $(\sim 56 \%)$ U.S. domains co-occur with a PV streamer positioned immediately upstream. Odds ratios of EPEs for days when a PV streamer occurs upstream of each domain indicate a strong, statistically significant association between EPEs and Rossby wave breaking. The strength of the EPE-Rossby wave breaking linkage, as measured by co-occurrence fractions and odds ratios, tends to increase with increasing EPE precipitation volume, such that the strongest linkage exists for widespread EPEs. Composite analyses reveal that Rossby wave breaking can result in widespread EPEs by establishing a persistent high-amplitude synoptic-scale wave pattern, within which strong poleward water vapor transport and ascent are forced over the EPE region immediately downstream of an elongated upper-level trough. Additional analyses demonstrate that, compared to corresponding null cases, Rossby wave breaking cases resulting in widespread EPEs exhibit a significantly higher-amplitude wave pattern that favors greater poleward transport of moist, conditionally unstable air and stronger ascent over the EPE region.
\end{abstract}

\section{Introduction}

Extreme precipitation events (EPEs) constitute a major natural hazard worldwide, often resulting in flooding that can pose a threat to human life (e.g., Ashley and Ashley 2008; Špitalar et al. 2014) and have costly socioeconomic and environmental impacts (e.g., Jongman et al. 2012; Gochis et al. 2015; NOAA/NCEI 2018b; White et al. 2019). Given these impacts, understanding the climatological characteristics and the governing dynamics of EPEs is of critical importance. This understanding may serve as a foundation for improvements to medium- and extended-range prediction and long-term climate projections of EPEs and their impacts.

Corresponding author: Benjamin J. Moore, benjamin.moore@ noaa.gov
The total precipitation at a given location is simply the time integral of the precipitation rate at the location over the duration of an event. Thus, EPEs result from a persistence of heavy precipitation (e.g., 5$10 \mathrm{~mm} \mathrm{~h}^{-1}$ ) for a sufficiently long duration (Doswell et al. 1996). Such occurrences require, in turn, that the basic ingredients for heavy precipitation-large water vapor supply, reduced static stability, and strong forcing for ascent-be established and maintained by the atmospheric flow and embedded weather systems. At midlatitudes, heavy precipitation is often linked to synoptic-scale baroclinic waves and associated extratropical cyclones (e.g., Pfahl and Wernli 2012). Conditions supportive of heavy precipitation are preferentially manifested in the warm sector of cyclones, where poleward fluxes of water vapor and heat often coincide with dynamical forcing for ascent along baroclinic zones and fronts (e.g., Browning 1990). In particular, heavy 
precipitation tends to occur in association with the poleward transport and deep ascent of warm, moist air in coherent airstreams within the warm sector called warm conveyor belts (WCBs; e.g., Harrold 1973; Carlson 1980; Wernli 1997; Pfahl et al. 2014). As described by Sodemann and Stohl (2013), the moist air parcels flowing into WCBs in the lower troposphere may be delivered via elongated corridors of strong water vapor flux, referred to as atmospheric rivers (e.g., Newell et al. 1992; Zhu and Newell 1998; Ralph et al. 2004), that typically coincide with a precold-frontal low-level jet (e.g., Browning and Pardoe 1973; Ralph et al. 2005). In some cases, moist air may be transported from remote tropical source regions along meridionally extensive flow corridors (e.g., Knippertz and Wernli 2010; Moore et al. 2012). The ascent in WCBs predominantly occurs in a slantwise sense along sloping moist isentropes within a baroclinic zone and results in mainly stratiform precipitation (e.g., Browning 1986). Embedded moist convection, promoting especially heavy precipitation, can also occur within the WCB (e.g., Neiman et al. 1993).

EPEs that are especially widespread (e.g., length scale of 500-1000 km) and long duration (e.g., $\geq 24 \mathrm{~h}$ ) have the potential to cause especially significant and spatially extensive flooding (e.g., Ulbrich et al. 2003; Houze et al. 2011; Grams et al. 2014; Gochis et al. 2015). These EPEs are favored within persistent high-amplitude baroclinic wave patterns in which the ingredients for heavy precipitation are established and maintained over an expansive area (e.g., Smith and Younkin 1972; Maddox et al. 1979; Moore et al. 2012). Cogent evidence from prior studies of EPEs in various regions of the world (e.g., Massacand et al. 1998; Knippertz and Martin 2007a,b; Sodemann et al. 2009; Schlemmer et al. 2010; Martius et al. 2013; Grams et al. 2014; Bosart et al. 2017; Lenggenhager et al. 2019) suggests that Rossby wave breaking along upper-level waveguides (e.g., Martius et al. 2010) may be a principal dynamical process for establishing such wave patterns. This prior research has collectively demonstrated that wave breaking scenarios resulting in EPEs tend to feature strong, persistent water vapor transport and ascent forced downstream of a high-amplitude, slow-moving upper-level trough that corresponds to an elongated filament of high potential vorticity (PV) air, referred to as a PV streamer (e.g., Appenzeller and Davies 1992).

Rossby wave breaking may occur when a wave strongly amplifies and undergoes a nonlinear evolution (e.g., Holton and Hakim 2013, their section 12.3.2). Under the influence of strong nonlinear effects, the wave experiences a rapid and irreversible deformation of material (i.e., PV) contours on isentropic surfaces (McIntyre and Palmer 1983, 1984). This process typically culminates in the formation of PV streamers (e.g., Martius et al. 2007). On synoptic scales, Rossby wave breaking is a manifestation of the latter part of baroclinic life cycles (e.g., Thorncroft et al. 1993), and is, therefore, linked to a complex 3D flow evolution that can strongly influence surface sensible weather. There are two distinct forms of Rossby wave breaking, anticyclonic wave breaking (AWB) and cyclonic wave breaking (CWB), which are characterized, respectively, by distinctive anticyclonic and cyclonic distortions of the upper-level PV field under the influence of anticyclonic and cyclonic background meridional shear. These two forms of wave breaking correspond, respectively, to the idealized LC1 and LC2 baroclinic life cycles of Thorncroft et al. (1993). The two life cycles differ with respect to the structure and evolution of cyclones, anticyclones, and baroclinic zones (e.g., Davies et al. 1991) as well as atmospheric rivers (e.g., Ryoo et al. 2013, 2015).

Climatological investigations have documented a key role for Rossby wave breaking in precipitation variability and the occurrence of EPEs in the European Alps (Martius et al. 2006), the Middle East (de Vries et al. 2018), and the western United States (Ryoo et al. 2013; Payne and Magnusdottir 2014; Hu et al. 2017). Such investigations are critical for determining the relevance of Rossby wave breaking to EPEs, but few have been conducted. The current study investigates linkages between EPEs in the central and eastern United States (i.e., the United States east of the Rocky Mountains) and Rossby wave breaking. This geographical focus is motivated by three factors: 1) the region is susceptible to heavy precipitation (e.g., Brooks and Stensrud 2000; Schumacher and Johnson 2006) and associated highimpact flooding (e.g., Ashley and Ashley 2008; Saharia et al. 2017); 2) EPEs in this region exhibit a proclivity to occur in association with baroclinic waves and associated phenomena (e.g., Maddox et al. 1979; Konrad 2001; Kunkel et al. 2012; Pfahl and Wernli 2012; Catto and Pfahl 2013; Pfahl et al. 2014), yet a possible link to Rossby wave breaking has not been investigated; 3) precursory case studies performed by the authors suggest that wave breaking can often play a key dynamical role in the occurrence of EPEs in the region. Analyses for two noteworthy EPEs linked to CWB and AWB, respectively, are shown in Figs. 1a and 1b. In each event, the upper-level PV field was highly deformed, and widespread heavy precipitation was produced downstream of a PV streamer.

The hypothesis posed herein is that Rossby wave breaking represents a principal dynamical pathway for the occurrence of EPEs in the central and eastern United States. This hypothesis is addressed through a 
(a)

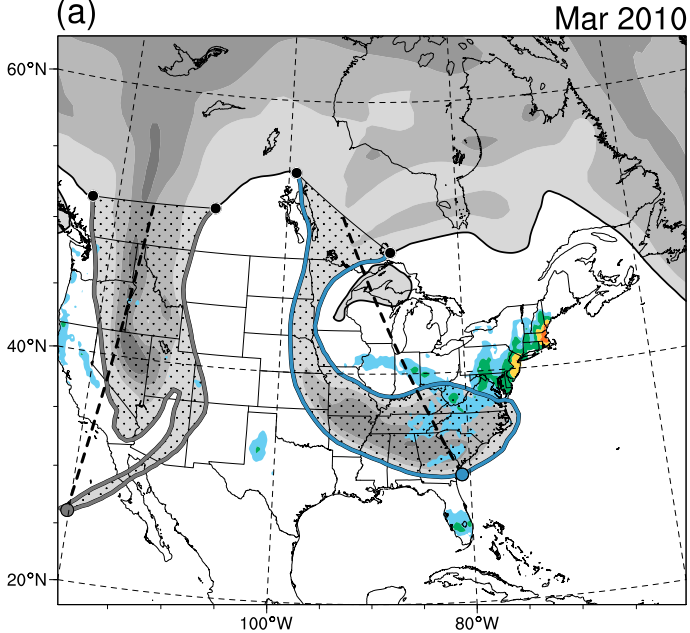

(b)

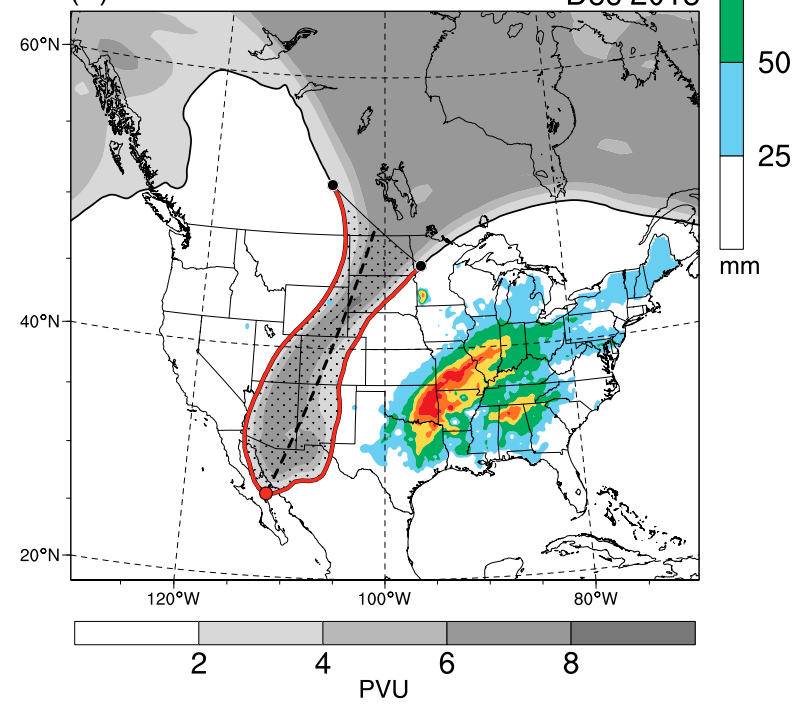

FIG. 1. 320-K PV (shaded in gray in PVU) from the ERAInterim dataset at (a) 1800 UTC 13 Mar 2010, and (b) 1800 UTC 26 Dec 2015. Accumulated precipitation (shaded in color in $\mathrm{mm}$ ) from the NCEP Climate Prediction Center Unified Precipitation Dataset for the 96-h period ending at 1200 UTC (a) 16 Mar 2010 and (b) 29 Dec 2015. Identified PV streamers are stippled (see section 2b). AWB, CWB, and neutral streamers are outlined in red, blue, and gray, respectively. Thick dashed black lines denote the orientation axes for the streamers.

systematic investigation employing climatologies of EPEs over the conterminous United States and PV streamers over North America for 1979-2015. The statistical linkage between EPEs and PV streamers is quantified as a means of deducing the dynamical relevance of Rossby wave breaking to EPEs. Composite analyses are then presented to provide synoptic-dynamic context for the linkage. The study primarily focuses on EPEs that exhibit exceptionally large and expansive precipitation amounts, referred to as "widespread" EPEs. Given their tendency to occur within high-amplitude baroclinic wave patterns (e.g., Maddox et al. 1979), these events are hypothesized to be strongly linked to Rossby wave breaking.

\section{Data and methods}

\section{a. Climatology of EPEs}

Precipitation data for 1979-2015 from the NCEP Climate Prediction Center Unified Precipitation Dataset (UPD; Higgins et al. 2000; NOAA/NCEP/CPC 2018) were utilized to construct a climatology of EPEs over the United States. The UPD comprises daily (12001200 UTC) gauge-based accumulated precipitation analyses on a $0.25^{\circ}$ grid over the conterminous United States for 1948-present. An object-based approach similar to that of Moore et al. (2015) was applied to identify EPEs. For this approach, an extreme precipitation threshold was defined at each grid point as the 99.5th percentile of daily precipitation for 1979-2015 (Fig. 2a). In a given daily precipitation map, grid points at which this threshold was exceeded were determined (Fig. 2b), and EPEs were then identified as coherent areas, or objects, of extreme grid points (Fig. 2c). In contrast to other object-based approaches (e.g., Hitchens et al. 2012), the grid points comprising an EPE were not required to directly adjoin each other; rather, gaps of $\leq 200 \mathrm{~km}$ were allowed between the grid points (e.g., Fig. 2c). A reference time, $t_{0}$, was defined for each EPE as 0000 UTC in the 24-h period of the EPE. The overall scale of each EPE was quantified as the total precipitation volume, an aggregate measure of the areal extent and intensity of precipitation, computed over all grid points in the EPE. In total, 51356 EPEs were identified over the United States.

Samples of EPEs in the central and eastern United States, respectively, were sought. As a visual guide for defining domains in which to select these samples, the geographical distribution of the top 1\% of EPEs (513 events) over the United States with respect to precipitation volume was mapped (Fig. 3). East of the Rocky Mountains the highest EPE frequencies (e.g., values $>0.15 \%$; Fig. 3a) are generally located 1 ) across the south-central United States, including parts of the southern Great Plains, the Gulf Coast states, and the Ohio River valley; and 2) in the eastern United States from the Southeast to southern New England. In the former region, frequencies are consistently high in winter (Fig. 3b), spring (Fig. 3c), and autumn (Fig. 3e), whereas in the latter region frequencies are highest in autumn (Fig. 3e). Two domains, referred to as the 
(a)

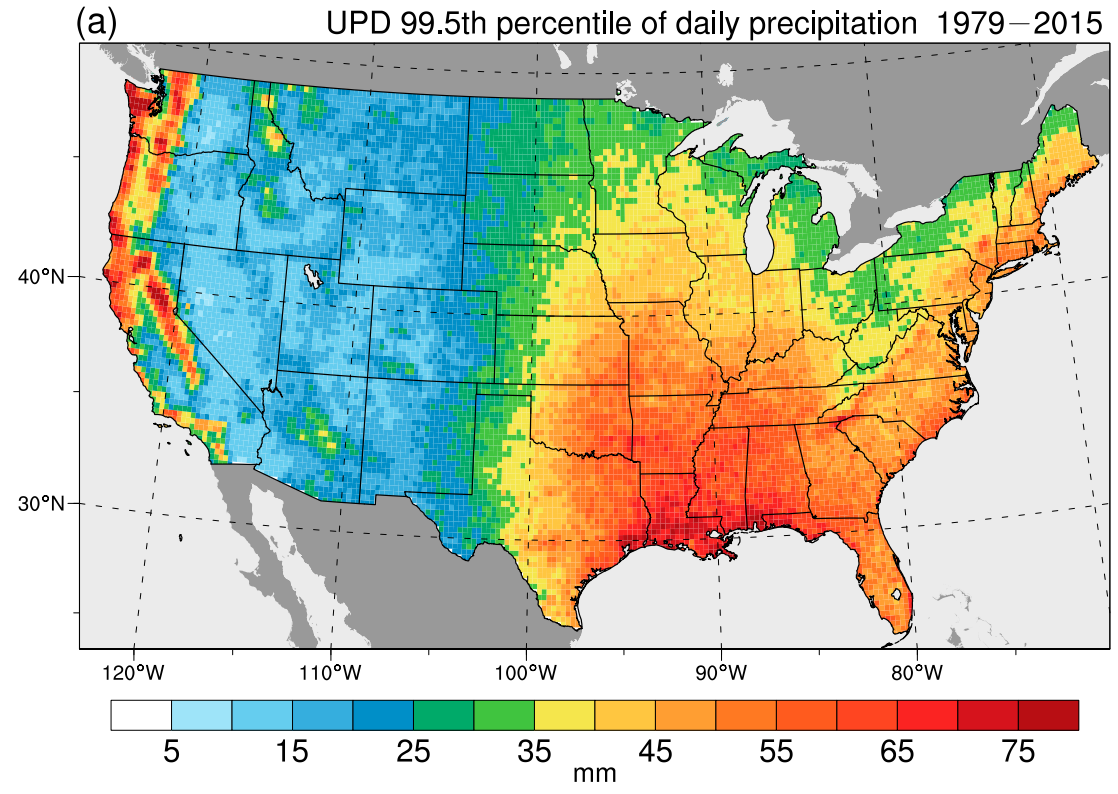

(b)

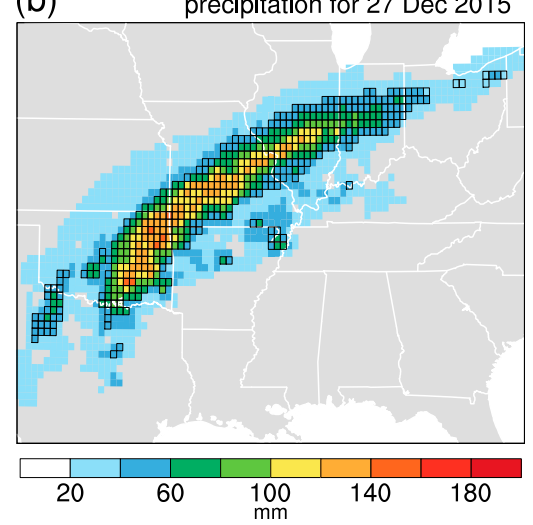

(c) EPE object identification

FIG. 2. (a) The 99.5th percentile of UPD daily (1200-1200 UTC) accumulated precipitation (shaded in mm) for 1979-2015. (b) 24-h UPD precipitation ending at 1200 UTC 27 Dec 2015 (shaded in mm; grid cells exceeding the extreme thresholds in Fig. 2a outlined in black). (c) Grid cells comprising the identified EPE in the precipitation field in (b) shaded in black.

central and eastern U.S. domains, were subjectively drawn over these two regions (Fig. 3a). All EPEs overlapping each domain were collected (central: 9037 events; eastern: 6591 events) and then sorted according to the precipitation volume produced in the domain. The top $2 \%$ of EPEs with respect to the precipitation volume for each domain were selected as widespread EPEs (central: 182 events; eastern: 133 events). EPEs occurring in a given domain on consecutive days were considered separate events.

\section{b. Climatology of Rossby wave breaking}

A climatology of Rossby wave breaking for 1979-2015 was constructed by implementing a method based on that of Wernli and Sprenger (2007). In this method, wave breaking is detected based on the occurrence of PV streamers, defined as narrow, elongated areas of high PV ( $>2$ PVU; 1 PVU $=10^{-6} \mathrm{~K} \mathrm{~kg}^{-1} \mathrm{~m}^{2} \mathrm{~s}^{-1}$ ) at the intersection of an isentropic surface with the dynamic tropopause (i.e., $\mathrm{PV}=2 \mathrm{PVU}$ ). Streamers were identified on the 310-, 320-, and 330-K surfaces. This range of surfaces was employed to account for seasonal variability in the height of the dynamic tropopause at midlatitudes (e.g., Wernli and Sprenger 2007). The ECMWF interim reanalysis (ERA-Interim; ECMWF 2009; Dee et al. 2011), obtained every $6 \mathrm{~h}$ on the native T255 $\left(\sim 0.7^{\circ} \times \sim 0.7^{\circ}\right)$ grid, was used for this and all other atmospheric analyses in the current study.

The PV streamer identification involved the following steps. The coordinates of the 2-PVU contour on a given 

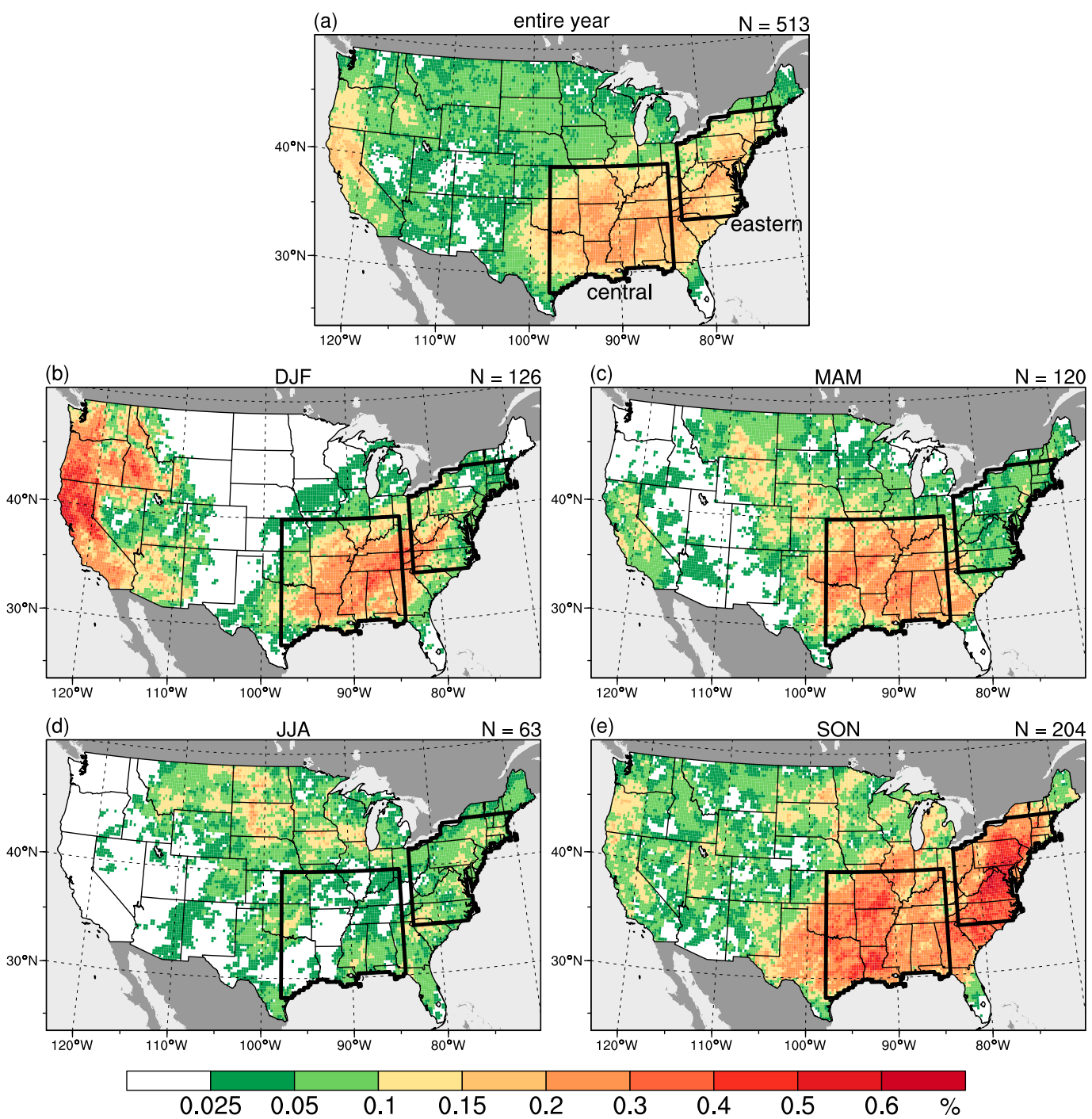

FIG. 3. Relative frequency (shaded in \%) of the top $1 \%$ of EPEs in the United States with respect to precipitation volume. Maps are shown for (a) the entire year, (b) December-February, (c) March-May, (d) June-August, and (e) September-November. The EPE sample sizes are indicated in the upper right of each panel. The black polygons outline the central and eastern U.S. domains described in the text.

isentropic surface were first extracted. ${ }^{1}$ A search was then conducted for contour segments for which the end points were separated by a great-circle distance of $<1000 \mathrm{~km}$ and by a contour length of $>3000 \mathrm{~km}$. These thresholds are larger and imply a lower maximum aspect ratio compared to those (i.e., $800 \mathrm{~km}$ and $1200 \mathrm{~km}$, respectively) used by Wernli and Sprenger (2007). The thresholds help to filter out spurious features and to retain large, elongated features that are

\footnotetext{
${ }^{1}$ The function get_isolines in the NCAR Command Language (version 6.5.0; UCAR/NCAR/CISL/TDD 2018) was used to extract the coordinates of the 2-PVU contour.
}

robust manifestations of Rossby wave breaking. Following Sprenger et al. (2013), contour segments with a length of $>15000 \mathrm{~km}$ were excluded. When multiple overlapping contour segments met the aforementioned criteria, only the longest segment was retained. A PV streamer was defined as a contiguous area of PV values $>2$ PVU delimited by a qualifying contour segment (stippling in Figs. 1a,b), and was categorized based on its tilt, as in Martius et al. (2007). To estimate tilt, an orientation axis was drawn from the midpoint between the end points of the streamer contour segment to the point $P$, defined as the point along the streamer contour segment located farthest, in terms of great-circle distance, from the midpoint. The tilt was 
quantified as the angle between a zonal base line, passing through $P$, and the orientation axis. Streamers with an angle of $\leq 75^{\circ}$ were ascribed to AWB (e.g., streamer outlined in red in Fig. 1b), whereas those with an angle of $\geq 105^{\circ}$ were ascribed to CWB (e.g., streamer outlined in blue in Fig. 1a). For the remaining streamers (e.g., streamer outlined in gray in Fig. 1a), constituting elongated meridionally oriented waves, the wave breaking type was considered ambiguous. These streamers were, accordingly, assigned to a neutral category.

\section{c. Climatologies of dynamically relevant flow features}

Climatologies of tropical moisture exports (TMEs; Knippertz and Wernli 2010) and WCBs, generated at ETH-Zurich [see Sprenger et al. (2017) for full details], were employed. These Lagrangian features represent processes, namely long-range water vapor transport and deep baroclinically forced ascent, respectively, that can be associated with the nexus between baroclinic waves and EPEs. As in Knippertz and Wernli (2010, their section 2), TMEs were identified as 168 -h forward trajectories that originate equatorward of $20^{\circ} \mathrm{N}$, terminate poleward of $35^{\circ} \mathrm{N}$, and maintain a moisture flux value of $\geq 100 \mathrm{~g} \mathrm{~kg}^{-1} \mathrm{~m} \mathrm{~s}^{-1}$. As in Madonna et al. (2014, their section 2), WCBs were identified as 48-h forward trajectories that originate below $790 \mathrm{hPa}$ and ascend $\geq 600 \mathrm{hPa}$ in the vicinity of an extratropical cyclone. All trajectories were computed using the ERAInterim with the Lagrangian Analysis Tool of Sprenger and Wernli (2015). The data were analyzed in the form of $1^{\circ}$ gridded binary fields, in which a value of 1 in a given grid cell at a given time indicates that at least one trajectory passed through that grid cell at that time. As in other studies (e.g., Schäfler et al. 2014; Röthlisberger et al. 2018), the WCB data were partitioned into inflow, ascent, and outflow fields by separately gridding trajectory segments located in the lower $(>800 \mathrm{hPa})$, middle $(800-400 \mathrm{hPa})$, and upper $(<400 \mathrm{hPa})$ troposphere, respectively. In addition to the TME and WCB climatologies, an Eulerian climatology of extreme vertically integrated water vapor transport (IVT) occurrences, defined as an exceedance of the 99th percentile of the IVT magnitude for 1979-2015 at a given grid point, was also employed and was similarly analyzed in the form of binary fields. The IVT was computed for the 1000300-hPa layer according to the method of Neiman et al. (2008). For the TME, WCB, and extreme IVT fields, contiguous areas of grid cells with a value of 1 are referred to as objects.

\section{d. Diagnosis of vertical motion}

Dynamically forced vertical motion was computed by solving the $\mathbf{Q}$-vector form of the quasigeostrophic
(QG) omega equation (Hoskins et al. 1978). Following the method of Keyser et al. (1988, 1992), a naturalcoordinate partitioning of the $\mathbf{Q}$-vector into cross- and along-isentrope components, referred to as $\mathbf{Q}_{\mathbf{n}}$ and $\mathbf{Q}_{\mathbf{s}}$, respectively, was performed. The calculations follow those described in Martin (2006, his section 2). The cross- and along-isentrope directions are designated by the unit vectors $\mathbf{n}$ and $\mathbf{s}$, respectively, defined such that $\mathbf{n}$ is directed along the local potential temperature gradient and $\mathbf{s}$ is directed $90^{\circ}$ counterclockwise from $\mathbf{n}$. The $\mathbf{Q}_{\mathbf{n}}$ and $\mathbf{Q}_{\mathbf{s}}$ vectors describe changes in the magnitude and direction, respectively, of the potential temperature gradient following the geostrophic wind. Frontogenesis (frontolysis) occurs where $\mathbf{Q}_{\mathbf{n}}$ points in the positive (negative) $\mathbf{n}$ direction. Counterclockwise (clockwise) rotation of the potential temperature gradient occurs where $\mathbf{Q}_{\mathbf{s}}$ points in the positive (negative) $\mathbf{s}$ direction. The vertical motions associated with the divergence of $\mathbf{Q}, \mathbf{Q}_{\mathbf{n}}$, and $\mathbf{Q}_{\mathbf{s}}$, referred to as $\omega_{\mathrm{QG}}, \omega_{n}$, and $\omega_{s}$, respectively, were computed via a standard successive overrelaxation routine (Press et al. 2007, their section 20.5.1) on an $f$ plane, using the Coriolis parameter for $40^{\circ} \mathrm{N}$ and a domain-averaged static stability.

\section{e. Statistical analysis of the relationship between EPEs and Rossby wave breaking}

The relationship between EPEs and Rossby wave breaking was investigated through a statistical analysis of the EPE and PV streamer climatologies. The initial step in this analysis was to test whether the conditional relative frequency of PV streamers given that an EPE occurs departs significantly from the expected or climatological streamer relative frequency. The relative frequency of PV streamers for all 6-h times between $t_{0}-24 \mathrm{~h}$ and $t_{0}+12 \mathrm{~h}$ for the central and eastern U.S. widespread EPEs was first calculated at each grid point as the percentage of times at which a PV streamer was identified on at least one of the three isentropic surfaces. Then, a 1000-iteration Monte Carlo resampling approach, similar to that in Quinting and Jones (2016, their section 2c), was applied. In each iteration, a random sample of $N$ dates was drawn, where $N$ is the size of the EPE sample of interest, and the times between $24 \mathrm{~h}$ prior to and $12 \mathrm{~h}$ after $0000 \mathrm{UTC}$ on each date were collected. A random date consisted of a random year between 1979 and 2015 and of a random day in that year selected from a list of all days within a 15-day window centered on $t_{0}$ for all EPEs in the sample. Thus, each random sample of dates had a similar subseasonal distribution to that of the EPE sample. For each random sample of dates, the relative PV streamer frequency at each grid point was computed, resulting in 1000 random relative 
streamer frequency maps. At a given grid point, the relative streamer frequency for a given sample of EPEs was designated significant if the value fit in the top or bottom $2.5 \%$ of the Monte Carlo distribution. The statistically significant values for each sample of EPEs were displayed as anomalies relative to the mean of the Monte Carlo distribution. In the resulting maps (Fig. 4), coherent areas of anomalously high relative streamer frequencies are located upstream of each EPE domain, highlighting favorable regions of PV streamer formation with respect to EPEs.

To further quantify the EPE-Rossby wave breaking relationship, subsets of PV streamers occurring over the favorable regions upstream of the EPE domains were selected. For each streamer type, a mask composed of grid points surrounding the relative streamer frequency anomaly maximum was defined (denoted by hatching in Figs. 4c-h). Grid points comprising the mask were required to have an anomaly value of $\geq 50 \%$ of the maximum value. The top $50 \%$ of streamers with respect to the area of overlap of the mask were then retained. If a given streamer was identified on multiple isentropic surfaces at a given 6-h time, only the surface on which the streamer exhibited the greatest overlap of the mask was considered. An EPE was considered to have cooccurred with a streamer and, therefore, with Rossby wave breaking if a streamer was identified between $t_{0}-24 \mathrm{~h}$ and $t_{0}+12 \mathrm{~h}$. An EPE associated with a streamer was categorized based on which type of streamer was identified most frequently between $t_{0}-24 \mathrm{~h}$ and $t_{0}+12 \mathrm{~h}$ for that EPE.

Tropical cyclones (TCs) frequently produce EPEs in the central and eastern United States (e.g., Prat and Nelson 2016). When matching EPEs to PV streamers, EPEs associated with a TC were excluded. An EPE was considered to be associated with a TC if at least one grid point for the EPE was located within $500 \mathrm{~km}$ of the center of a TC during the 48 -h period centered on $t_{0}$. The TC data were obtained from The International Best Track Archive for Climate Stewardship dataset (Knapp et al. 2010; NOAA/NCEI 2018a). EPEs that were neither associated with a PV streamer nor with a TC were left unclassified.

The statistical association between the EPEs and PV streamer subsets was quantified using the odds ratio (Wilks 2011, his section 8.2.2). This metric is calculated as

$$
\text { odds ratio }=\frac{P(E \mid S)[1-P(E \mid N)]}{P(E \mid N)[1-P(E \mid S)]}
$$

Here, $P(E \mid S)$ is the conditional probability of occurrence of an EPE given that a PV streamer occurs and is calculated for all days (1200-1200 UTC) overlapping the period between $12 \mathrm{~h}$ prior to and $24 \mathrm{~h}$ after the time of a streamer. $P(E \mid N)$ is the conditional probability of occurrence of an EPE given that a PV streamer does not occur and is calculated for days not associated with a streamer (i.e., nonstreamer days). The odds ratio summarizes the joint probability distribution of two binary events (i.e., EPEs and PV streamers). An odds ratio value of $>1$ indicates a positive association between EPEs and streamers, such that the likelihood of an EPE occurring when a streamer occurs is enhanced relative to when a streamer does not occur. A value of $<1$ indicates a negative association, such that likelihood of an EPE occurring when a streamer occurs is reduced relative to when a streamer does not occur. A value of 1 indicates that EPEs and streamers are independent events. This metric has been applied to examine the modulation of weather extremes by high-amplitude Rossby waves (Röthlisberger et al. 2016) and atmospheric blocking (Lenggenhager and Martius 2019).

To reduce effects of differences in seasonality between streamer and nonstreamer days in the odds ratio calculations, samples of nonstreamer days with a similar subseasonal distribution to the streamer days were obtained using a 1000-iteration resampling approach. In each iteration, a random sample of $N$ dates was selected, where $N$ is the size of a given sample of streamer days. A random date consisted of a random year between 1979 and 2015 and of a random day selected from a list of all days within a 15-day window centered on the streamer days. Any streamer day randomly drawn in this manner was discarded, and new dates were drawn until a sample of $N$ nonstreamer days was obtained. The average $P(E \mid N)$ value for the random samples was then used in the odds ratio calculation [Eq. (1)]. The null hypothesis that PV streamers and EPEs are independent (i.e., odds ratio of unity) was tested using a 1000-iteration bootstrap test (Wilks 2011, his section 5.3.5).

\section{Statistical relationship between EPEs and Rossby wave breaking}

In this section, the statistical relationship between EPEs and Rossby wave breaking is explored. The tendency for EPEs to co-occur with PV streamers is assessed, and the statistical association between EPEs and PV streamers is quantified in terms of the odds ratio.

\section{a. Co-occurrence of EPEs with PV streamers}

The conditional relative frequency of PV streamers for the widespread EPEs is significantly enhanced relative 

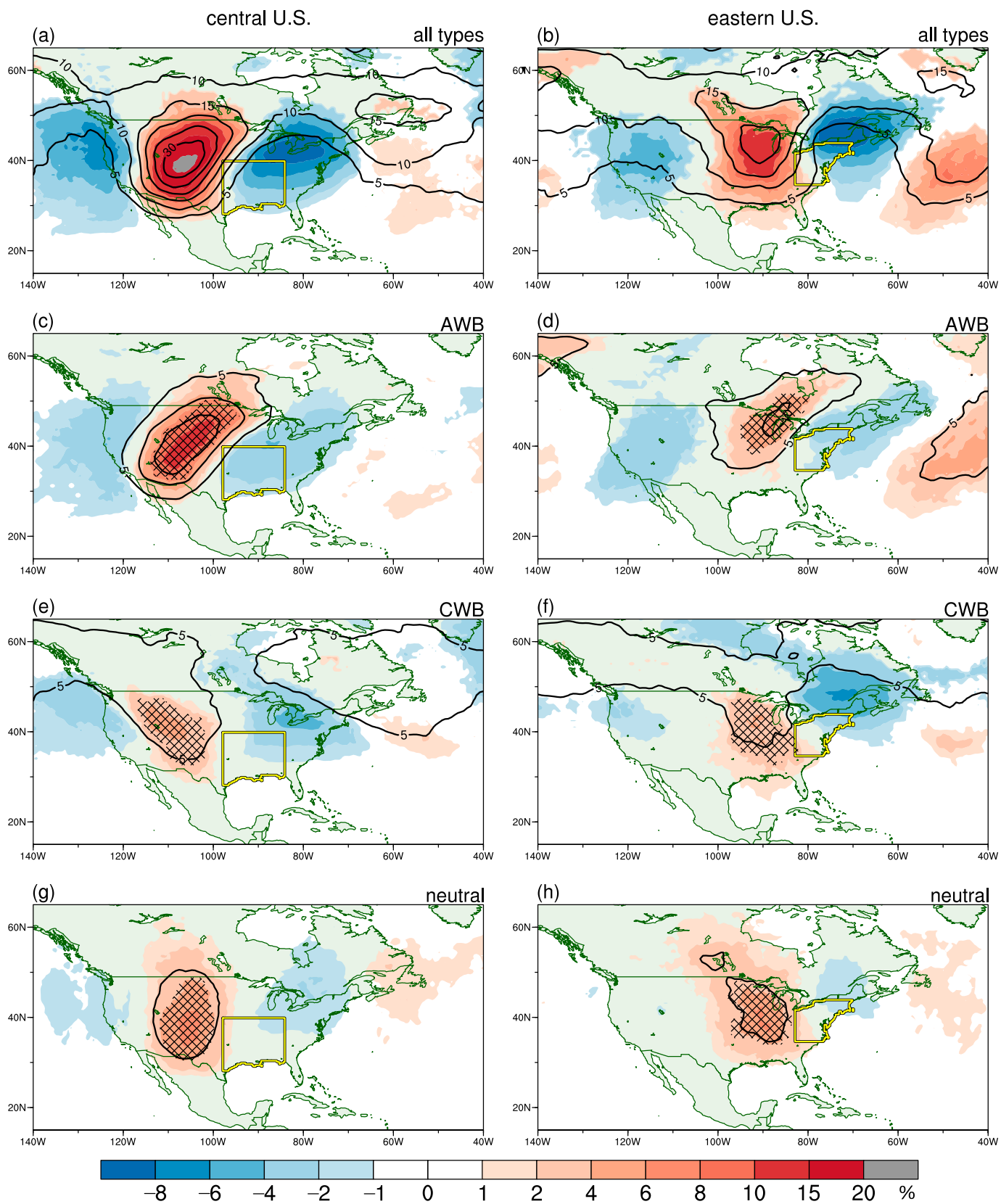

FIG. 4. Relative PV streamer frequency (black contours, every $5 \%$ ) and frequency anomaly (shaded in \%; only values statistically significant at the $95 \%$ confidence level plotted) corresponding to the (left) central $(N=182)$ and (right) eastern $(N=133)$ U.S. widespread EPEs. Analyses are shown for (a),(b) all streamer types, (c),(d) AWB streamers, (e),(f) CWB streamers, and (g),(h) neutral streamers. The hatched regions in (c)-(h) denote the masks used to select subsets of PV streamers (see section 2e). Yellow polygons outline the central and eastern U.S. domains.

to climatology immediately upstream of the central and eastern U.S. domains (Figs. 4a,b), indicating a tendency for EPEs in the two domains to occur in conjunction with Rossby wave breaking. This general pattern is evident for each streamer type (Figs. $4 \mathrm{c}-\mathrm{h}$ ). The maximum streamer frequency and frequency anomaly values are overall higher for the central U.S. EPEs (Fig. 4a) than for the eastern U.S. EPEs (Fig. 4b), indicating that the former events more frequently involve Rossby wave breaking.

Figure 5 displays the fraction of EPEs that co-occur with PV streamers and TCs for different precipitation volume percentile bins. Majorities of the widespread EPEs (i.e., highest volume bin) in the central $(\sim 79 \%$; 

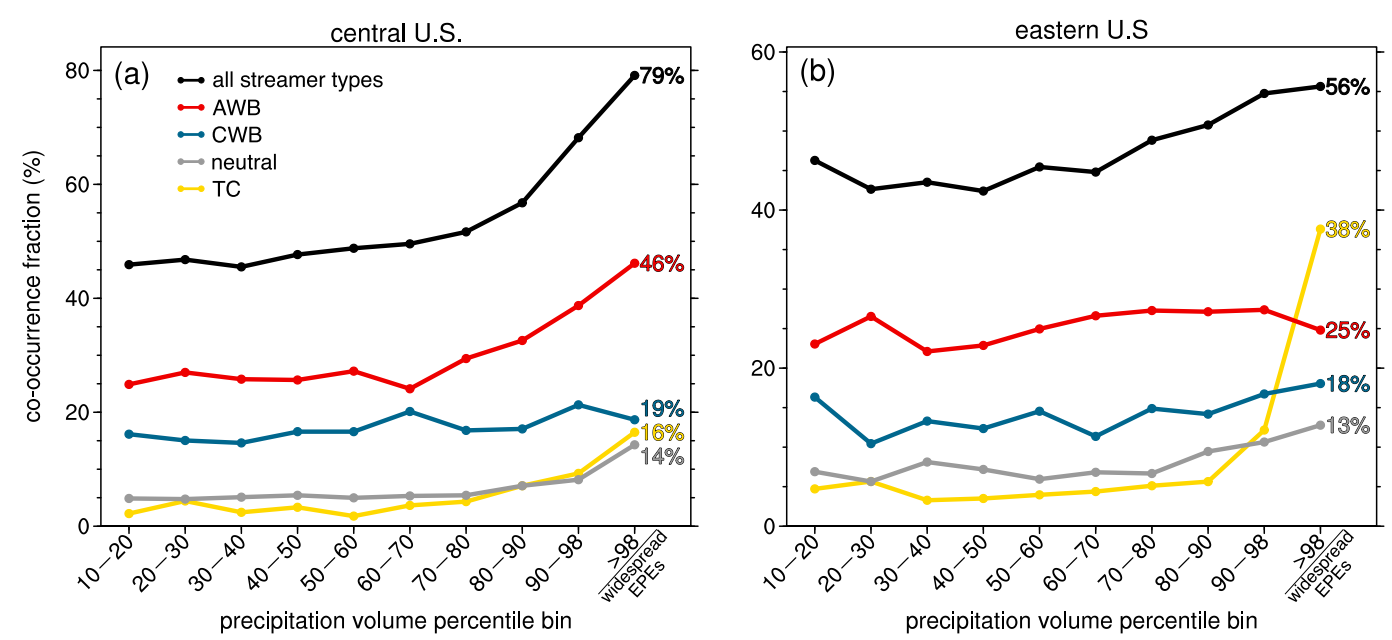

FIG. 5. The fraction of EPEs in different precipitation volume percentile bins in the (a) central and (b) eastern U.S. domains co-occurring with all PV streamer types (black), AWB streamers (red), CWB streamers (blue), neutral streamers (gray), and TCs (yellow). Values for the highest bin (i.e., widespread EPEs) are listed.

144 of 182 events) and eastern ( $~ 56 \% ; 74$ of 133 events) U.S. domains co-occur with a PV streamer. TCs account for a larger fraction of the widespread EPEs in the eastern United States $(\sim 38 \% ; 50$ of 133 events) than in the central United States $(\sim 16 \%$; 30 of 182 events). The widespread EPEs that remained unclassified (central: 8 events; eastern: 9 events) involved broad troughs that did not qualify as PV streamers or, in some cases, cut-off lows (not shown). For both domains, the fraction of EPEs co-occurring with streamers and with TCs tends to increase with increasing precipitation volume such that the widespread EPEs exhibit the largest fractions (Figs. 5a,b). These results demonstrate the strong relevance of Rossby wave breaking to widespread EPEs and justify our emphasis of these EPEs. EPEs in all bins tend to co-occur with AWB streamers more frequently than with CWB or neutral streamers (Figs. 5a,b), consistent with the predominance of AWB streamers over the other two types in the subsets under consideration (Table 1). PV streamers are much more common than EPEs, and only small fractions of the streamer subsets are linked to widespread EPEs (Table 1).

The monthly relative frequency of the widespread EPEs and, for reference, all EPEs regardless of scale in the central and eastern U.S. domains are depicted in Fig. 6. For both domains, a pronounced seasonal cycle is evident when considering all EPEs, with the frequency maximizing in the summer and minimizing in the winter (Figs. 6a,b). The monthly relative frequency of the widespread EPEs differs markedly from that of all EPEs. In the central United States (Fig. 6a), widespread EPEs occur most frequently in September and least frequently in June. Moreover, the widespread EPE frequency is considerably higher in the winter and transition seasons than in the summer. All of the widespread EPEs in June-August, a significant majority of those in September, and some of those in October occur in conjunction with TCs (Fig. 6a), consistent with the climatology of TC landfalls and associated precipitation in this region (e.g., Larson et al. 2005). Rossby wave breaking accounts for a large majority of the central U.S. EPEs in October-May and some of those in September (Fig. 6a). The low frequency of widespread EPEs and the lack of wave breaking-related EPEs in the central U.S. domain in the summer likely relate to weak background baroclinicity and are consistent with lower climatological frequencies of PV streamers upstream of this domain in the summer months relative to the other months (Fig. 6c). Widespread EPEs in the central United States co-occur with AWB more frequently than CWB in September-January (Fig. 6a). Conversely, in February-May the EPEs co-occur with CWB with a similar or greater frequency compared to AWB (Fig. 6a).

In the eastern United States (Fig. 6b), widespread EPEs occur most frequently in September and least frequently in July. Rossby wave breaking-related EPEs predominantly occur in the nonsummer months and constitute a majority of the EPEs in October-May (Fig. 6b). The low frequency of wave breaking-related EPEs in summer is consistent with a minimization of the PV streamer frequency upstream of the eastern U.S. domain (Fig. 6d). In all months except December, January, April, and July, widespread EPEs co-occur 
TABLE 1. The total number of PV streamer days (first number) and the number of PV streamer days matched to a widespread EPE (second number) for the central and eastern U.S. domains. The percentage of PV streamer days matched to a widespread EPE is given in parentheses.

\begin{tabular}{ccc}
\hline \hline PV streamer type & Central United States & Eastern United States \\
\hline AWB & $3942,84(2.1 \%)$ & $3415,33(1.0 \%)$ \\
CWB & $2331,34(1.5 \%)$ & $2407,24(1.0 \%)$ \\
Neutral & $638,26(4.1 \%)$ & $830,17(2.0 \%)$ \\
All types & $6911,144(2.1 \%)$ & $6652,74(1.1 \%)$ \\
\hline
\end{tabular}

more frequently with AWB than with CWB (Fig. 6b). TCs account for all widespread EPEs in July, large majorities of those in August and September, and some in June, October, and November (Fig. 6b), in agreement with the climatology of TC landfalls and associated precipitation in this region (e.g., Larson et al. 2005).

\section{b. Odds ratios}

Figure 7 shows maps of the odds ratio of EPEs, regardless of scale, for days on which a PV streamer occurs upstream of the central and eastern U.S. domains. For each streamer type, statistically significant odds ratios exceeding unity occur across portions of the central (Figs. 7a,c,e) and eastern (Figs. 7b,d,f) U.S. domains. These odds ratios occur in expansive areas downstream of the PV streamer selection masks and the collocated composite trough axes and often extend well outside the domains of interest. For instance, the CWB streamers for the central U.S. domain (Fig. 7c) are associated with widespread odds ratios exceeding unity across the northcentral United States. Overall, these maps illustrate a significant statistical association between the occurrence of a PV streamer and the occurrence of extreme precipitation downstream.

Figure 8 displays $P(E \mid S)$ and $P(E \mid N)$ from Eq. (1) and the odds ratios for EPEs in each domain with a precipitation volume exceeding increasing thresholds. In both the central (Fig. 8a) and eastern (Fig. 8b) U.S. domains, $P(E \mid S)$ exceeds $P(E \mid N)$ for all wave breaking types and for all precipitation volume thresholds. The odds ratios all exceed unity and are statistically significant (Figs. 8c,d), indicating a significant association between Rossby
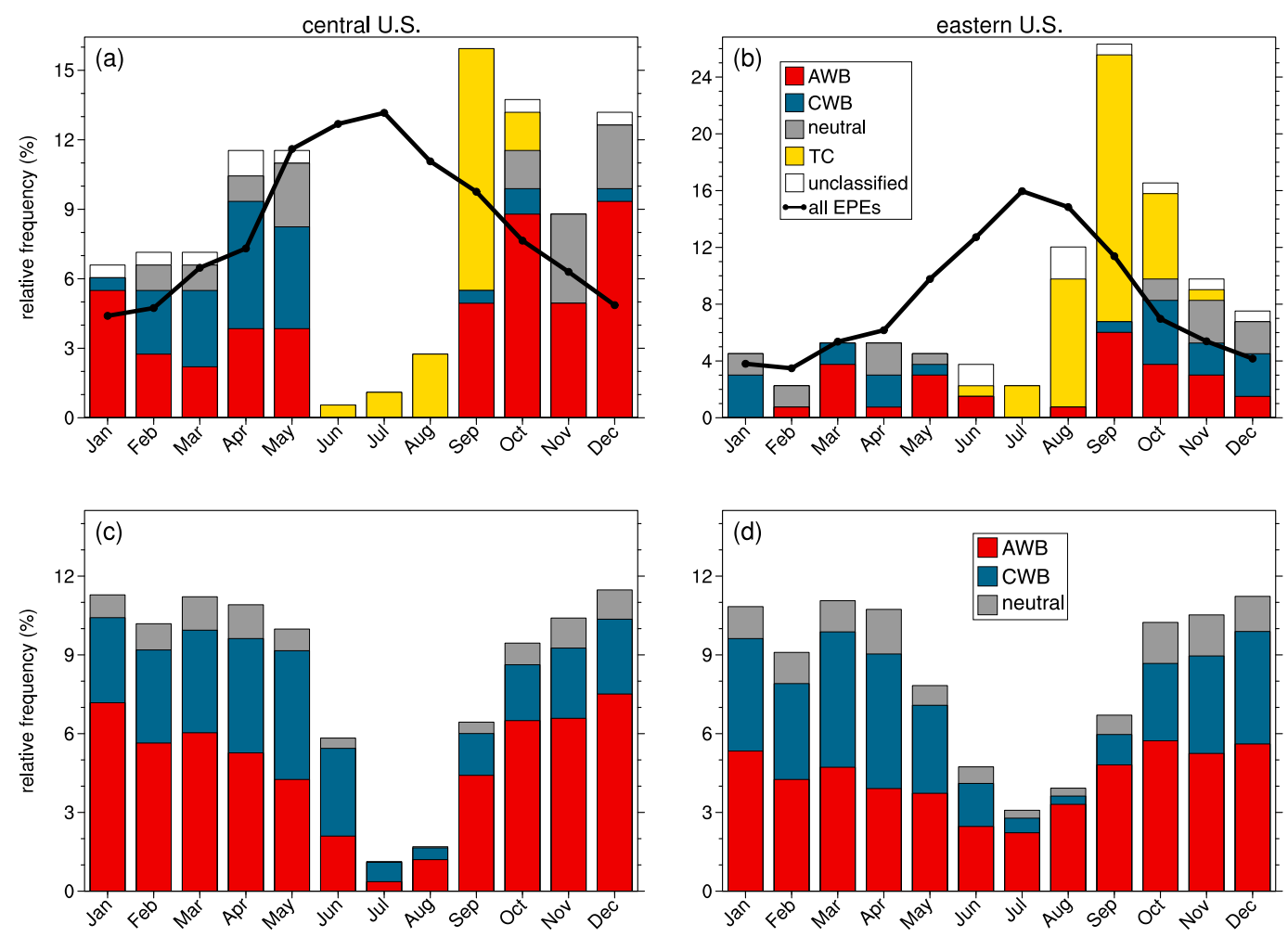

FIG. 6. (top) The monthly relative frequency of all EPEs (black curve) and widespread EPEs (bars) for the (a) central and (b) eastern U.S. domains. The fraction of the widespread EPEs assigned to each category is indicated by the shading according to the legend in (b). (bottom) The monthly relative frequency of PV streamers occurring upstream of the (c) central and (d) eastern U.S. domains. The fraction of PV streamers assigned to the AWB, CWB, and neutral categories is indicated by the shading according to the legend in $(\mathrm{d})$. 

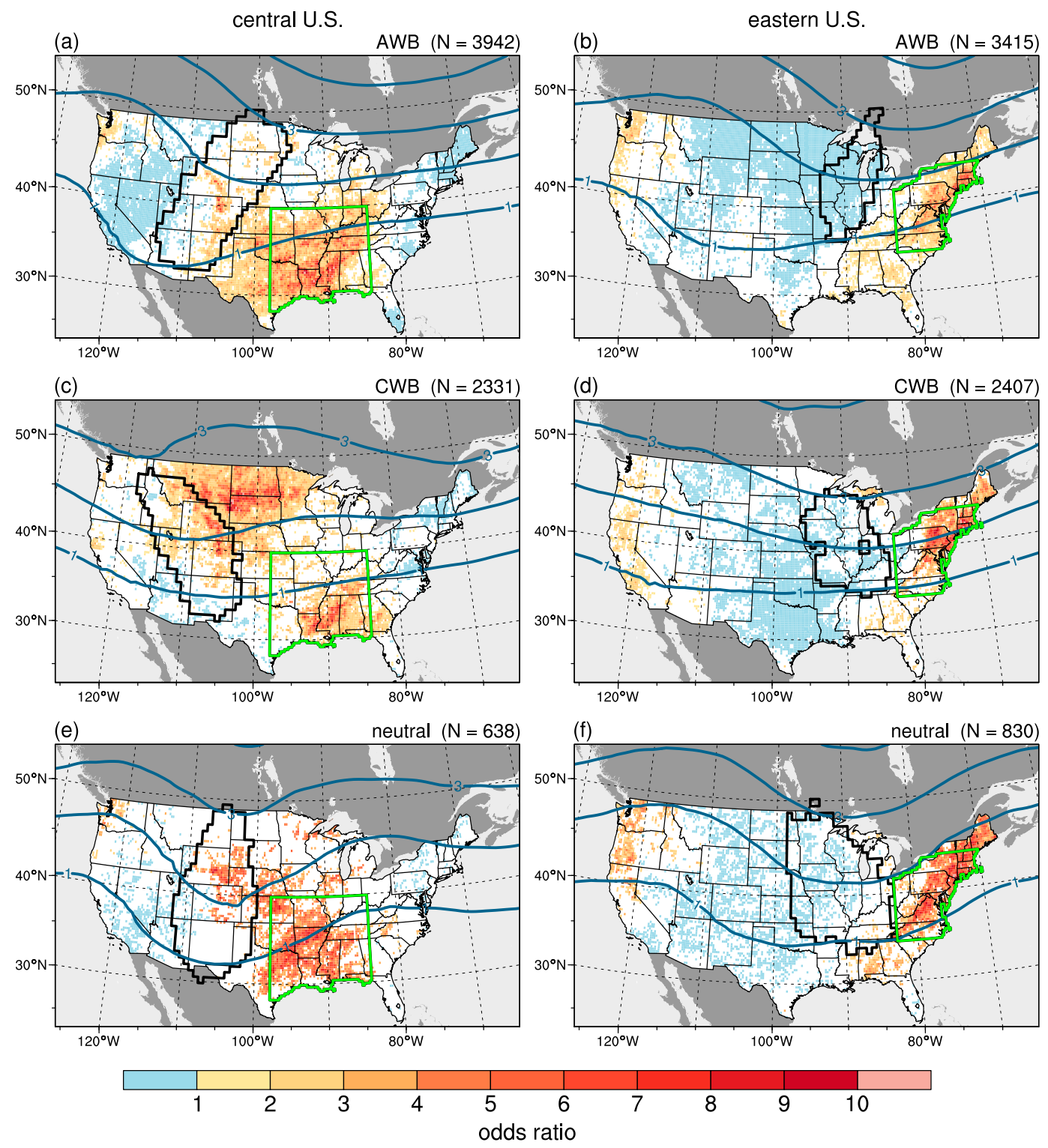

FIG. 7. The odds ratio of EPEs regardless of scale for days on which a PV streamer occurs upstream of the (left) central and (right) eastern U.S. domains. Maps are shown for (a),(b) AWB, (c),(d) CWB, and (e),(f) neutral streamers. Grid points at which the odds ratio is not statistically significant at the $95 \%$ confidence level are shaded in white. The composite 320-K PV (dark blue contours every 1 PVU) for each subset of streamer days is overlaid, and the masks used to select the subsets (Figs. 4c-f; see section 2e) are outlined in black. The sample size of streamer days is indicated in the top right of each panel. Green polygons outline the central and eastern U.S. domains.

wave breaking and EPEs in the two domains. For both domains, the odds ratios increase with increasing volume threshold, and the values at the highest threshold (i.e., widespread EPEs) are well in excess of unity (Figs. 8c,d). Thus, an exceptionally strong association exists between Rossby wave breaking and widespread EPEs. For both domains, the odds ratios for neutral streamers are greater than those for AWB and CWB streamers (Figs. 8c,d), indicating that neutral streamers are especially favorable for EPEs. For the central United States, the odds ratios are greater for AWB than for CWB streamers at all thresholds (Fig. 8c). For the eastern United States, the odds ratios for AWB and CWB streamers are similar, except at the highest threshold where the odds ratio for CWB streamers is considerably greater than that for AWB streamers (Fig. 8d). In aggregate, the EPE odds ratios for the central United States are greater than those for the 

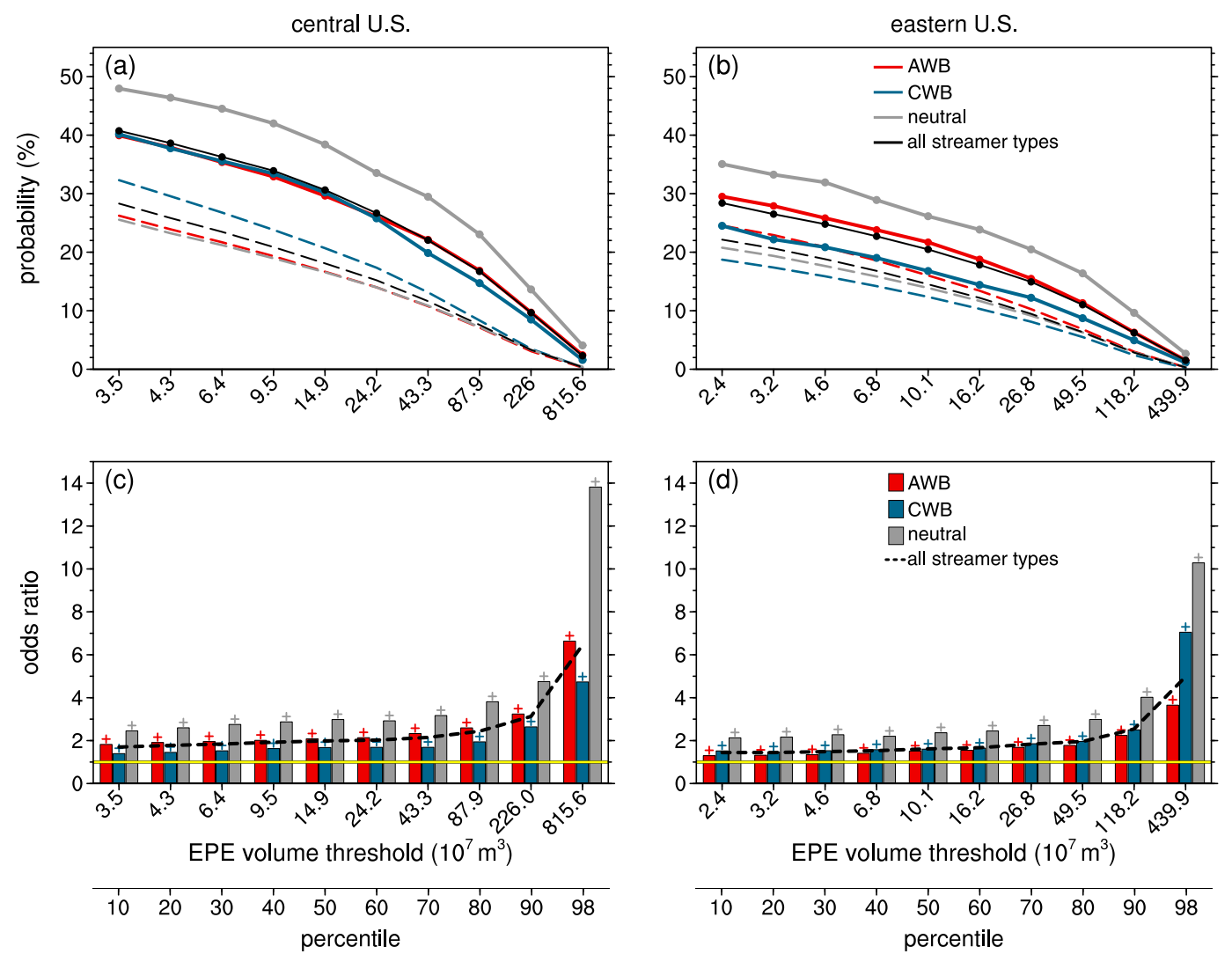

FIG. 8. (top) The probability of occurrence (solid curves) and (bottom) the odds ratio of EPEs in the (a),(c) central and (b),(d) eastern U.S. domains exceeding increasing precipitation volume thresholds, corresponding to climatological percentiles [indicated by the tick marks below (c),(d)], for days on which a PV streamer occurs upstream of the domains. Values in (a)-(d) are shown for AWB (red), CWB (blue), and neutral (gray) streamers and for all streamer types combined (black). In (a),(b), probabilities for the corresponding samples of nonstreamer days are indicated by dashed curves. In (c),(d), the dashed black curve indicates the odds ratios for all streamer types, plus symbols above bars denote odds ratio values that are statistically significant at the $95 \%$ confidence level, and the yellow line denotes an odds ratio value of unity.

eastern United States (cf. dashed black curves in Figs. 8c,d), indicating a stronger EPE-Rossby wave breaking association for the central United States than for the eastern United States.

The odds ratio calculations in Fig. 7 were repeated, except for extreme IVT, TME, and WCB ascent objects rather than for EPEs. The results are summarized in Table 2 as area-averaged and maximum odds ratios within the central and eastern U.S. domains, computed using only statistically significant (95\% confidence) gridpoint values. The odds ratios of the three flow features all exceed unity, providing statistical confirmation of a link between EPE-supporting processes and Rossby wave breaking. In both domains, the odds ratios of the three flow features are greater for neutral streamers than for AWB and CWB streamers, suggesting that neutral streamers are particularly conducive to strong and extensive moist poleward flow.

\section{c. Sensitivity to the PV streamer selection criteria}

The EPE-PV streamer co-occurrence fractions and the odds ratios were sensitive to the mask overlap threshold imposed to select the streamers upstream of the central and eastern U.S. domains (see section 2e), as demonstrated in Table 3 for the widespread EPEs. Specifically, as the minimum overlap threshold is increased and thus fewer streamers are retained, the co-occurrence fractions decrease while the odds ratios tend to increase. Despite this sensitivity, the qualitative interpretation of the results is unaffected.

\section{Composite perspective on widespread EPEs linked to Rossby wave breaking}

Composite analyses are herein presented to provide synoptic-dynamic context for the linkage between 
TABLE 2. Area-averaged and maximum odds ratios of extreme IVT objects, TME objects, and WCB ascent objects within the central and eastern U.S. domains for days on which a PV streamer occurs upstream of the domains. The values are computed using only statistically significant ( $>95 \%$ confidence) gridpoint values. The maximum odds ratios are shown in parentheses.

\begin{tabular}{|c|c|c|c|c|c|c|}
\hline & \multicolumn{3}{|c|}{ Central United States } & \multicolumn{3}{|c|}{ Eastern United States } \\
\hline & AWB & CWB & Neutral & AWB & CWB & Neutral \\
\hline Extreme IVT & $3.62(6.50)$ & $3.70(6.75)$ & $7.8(15.69)$ & $2.45(4.11)$ & $2.55(4.18)$ & $4.23(6.98)$ \\
\hline TME & $1.30(1.69)$ & $1.33(1.63)$ & $1.63(2.23)$ & $1.23(1.61)$ & $1.31(1.78)$ & $1.51(2.30)$ \\
\hline WCB ascent & $2.99(6.98)$ & $2.82(5.19)$ & $5.17(11.75)$ & $2.75(3.72)$ & $2.34(3.76)$ & $4.13(6.03)$ \\
\hline
\end{tabular}

EPEs and Rossby wave breaking. Analyses are presented for all widespread EPEs that co-occurred with a PV streamer combined (Figs. 9-11) to elucidate the general characteristics of EPEs linked to wave breaking. Analyses for AWB and CWB cases (Figs. 12 and 13) are then compared to identify dynamical differences between the distinct wave breaking scenarios. Anomalies were calculated relative to a smoothed daily 1979-2009 climatology, computed as in Bosart et al. (2017), and were tested for statistical significance using a 1000-iteration bootstrap test. Relative frequency anomalies of WCB and TME objects were calculated in the same manner as were the PV streamer relative frequency anomalies (see section $2 \mathrm{e})$.

\section{a. Characteristics of EPEs linked to Rossby wave breaking}

The central and eastern U.S. composites in Figs. 9-11 are qualitatively similar and are therefore discussed in tandem. Composites of $320-\mathrm{K} \mathrm{PV}$ and PV anomalies (Figs. 9a and 10a) display a high-amplitude wave pattern across North America that features an elongated trough (i.e., PV streamer) upstream of the EPE region and a prominent ridge downstream. This upper-level wave pattern is linked to an anomalous lower-level pattern comprising a surface low and high associated with expansive negative and positive sea level pressure anomalies, respectively (Figs. 9b and 10b). The low and high are displaced immediately east of the corresponding upper-level trough and ridge axes and the concurrent PV anomalies (Figs. 9a,b and 10a,b), revealing an upshear wave tilt with height suggestive of baroclinic instability. The upper-level PV pattern is associated with a thermal trough-ridge pattern in the $1000-500-\mathrm{hPa}$ thickness field that features a baroclinic zone stretching across the EPE region (Figs. 9b and 10b). The baroclinic zone is reflected aloft by a southwesterly 250-hPa jet streak positioned near the upper-level ridge axis (Figs. 9a and 10a). Warm-air advection and upward $700-\mathrm{hPa} \omega_{\mathrm{QG}}$ occur over the EPE region beneath the equatorward entrance region of the jet streak (Figs. 9b and 10b), where anomalous poleward lower-tropospheric flow (Figs. 9c and 10c) between the surface low and high intersects the baroclinic zone. The QG ascent is associated with large positive relative frequency anomalies of WCB ascent objects (Figs. 9e and 10e).

The anomalous poleward flow into the EPE region is related to a meridionally elongated corridor of anomalously strong IVT (Figs. 9d and 10d), resembling an atmospheric river, and an accompanying plume of anomalously high total column water vapor (Figs. 9c and 10c) extending into the EPE region. Relative frequency anomalies for WCB inflow objects are maximized along the IVT corridor equatorward of the baroclinic zone, and those for WCB outflow objects are maximized on the poleward side of the baroclinic zone within the upper-level ridge (Figs. 9e and 10e). The configuration of WCB inflow, ascent, and outflow indicated in Figs. 9e and $10 \mathrm{e}$ reflects deep slantwise ascent along a sloping baroclinic zone.

The IVT corridor in the central U.S. composite (Fig. 9d) stretches anticyclonically from the tropics over the Caribbean Sea and the Gulf of Mexico into the EPE

TABLE 3. The co-occurrence fraction and the odds ratio of widespread EPEs corresponding to the top $90 \%, 75 \%, 50 \%, 25 \%$, and $10 \%$ of PV streamers with respect to the area of overlap of the selection masks denoted by the hatched regions in Figs. $4 \mathrm{c}-\mathrm{h}$.

\begin{tabular}{ccccc}
\hline \hline & \multicolumn{2}{c}{ Central United States } & & \multicolumn{2}{c}{ Eastern United States } \\
\cline { 2 - 3 } PV streamer sample & Co-occurrence fraction (\%) & Odds ratio & & Co-occurrence fraction (\%) \\
\hline top 90\% & 81.3 & 4.02 & 60.9 & Odds ratio \\
top 75\% & 80.8 & 5.08 & 60.9 & 4.25 \\
top 50\% & 79.1 & 6.63 & 55.6 & 4.75 \\
top 25\% & 69.8 & 6.13 & 45.9 & 3.24 \\
top 10\% & 52.7 & 6.65 & 35.3 & 5.35 \\
\hline
\end{tabular}


(a)

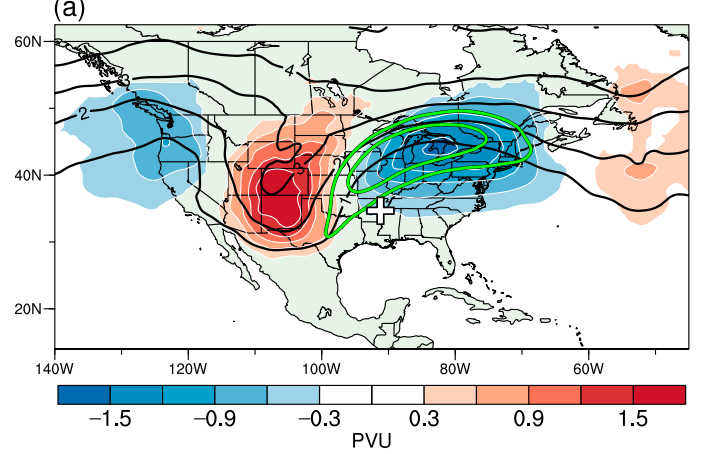

(c)

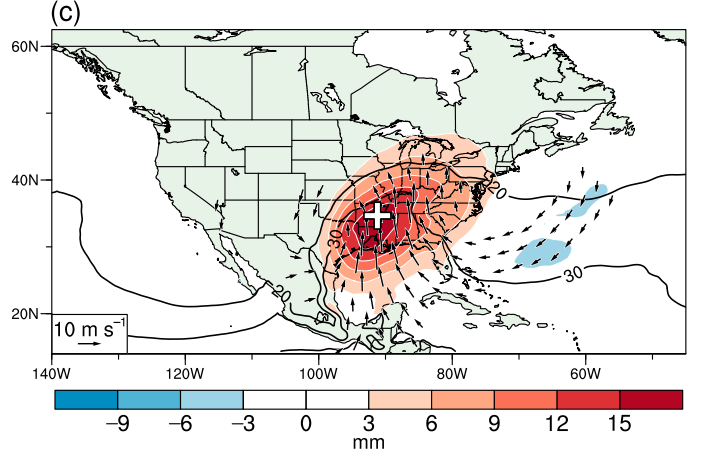

(e)

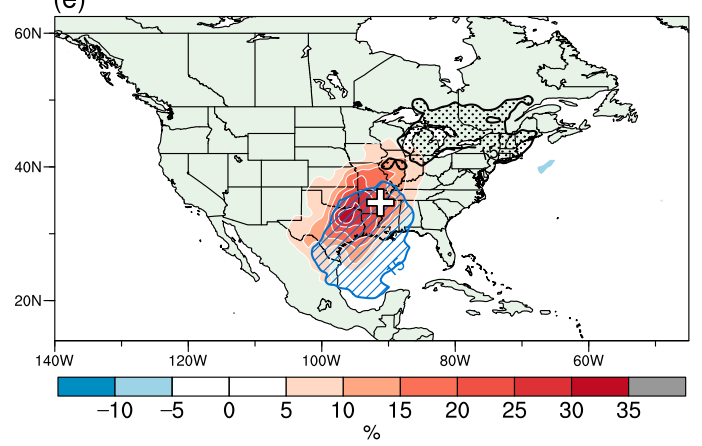

(b)

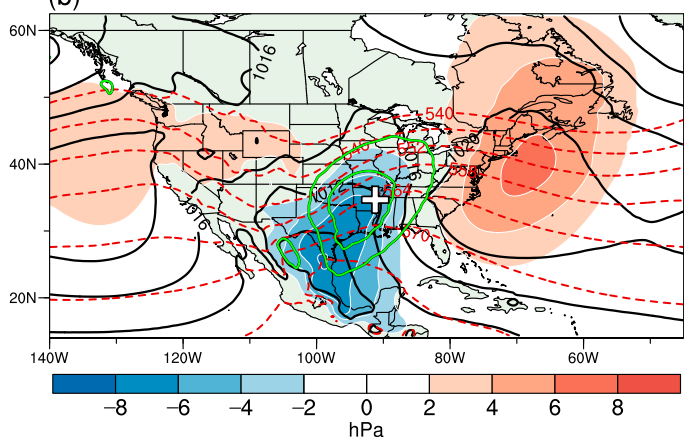

(d)

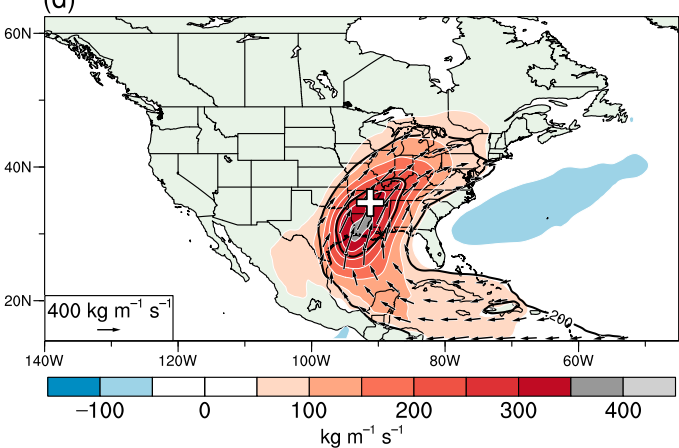

(f)

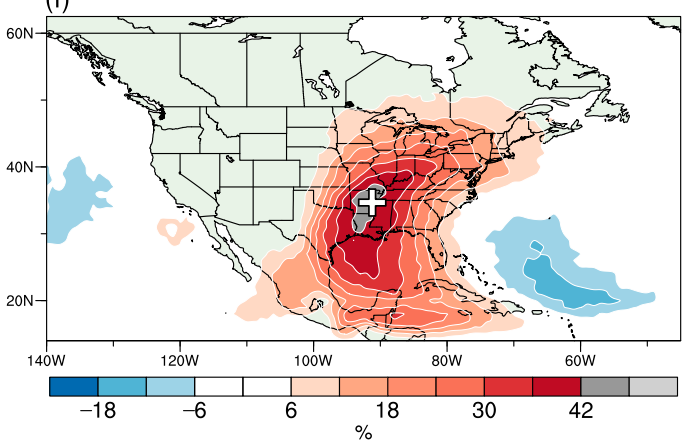

FIG. 9. Composite analyses for the central U.S. widespread EPEs that co-occurred with Rossby wave breaking $(N=144)$. (a) 320-K PV (black contours every 1 PVU), 320-K PV anomaly (shaded in PVU), and 250-hPa wind speed (green contours every $5 \mathrm{~m} \mathrm{~s}^{-1}$ starting at $40 \mathrm{~m} \mathrm{~s}^{-1}$ ) at $t_{0}$. (b) Sea level pressure (black contours every $4 \mathrm{hPa}$ ), sea level pressure anomaly (shaded in $\mathrm{hPa}$ ), $700-\mathrm{hPa} \omega_{\mathrm{QG}}$ (green contours every $0.03 \mathrm{~Pa} \mathrm{~s}^{-1}$; negative values only), and 1000-500-hPa thickness (red contours every 6 dam between 540 and $576 \mathrm{dam}$ ) at $t_{0}$. (c) Total column water vapor (black contours every $10 \mathrm{~mm}$ starting at $20 \mathrm{~mm}$ ), total column water vapor anomaly (shaded in mm), and $850-\mathrm{hPa}$ wind anomaly (vector scale in lower left) at $t_{0}$. (d) IVT vectors (vector scale in lower left), magnitude (black contours every $200 \mathrm{~kg} \mathrm{~m}^{-1} \mathrm{~s}^{-1}$ ), and magnitude anomaly (shaded in $\mathrm{kg} \mathrm{m}^{-1} \mathrm{~s}^{-1}$ ) at $t_{0}$. (e) Relative frequency anomalies of WCB inflow objects ( $>15 \%$ hatched in blue) at $t_{0}-24 \mathrm{~h}$, ascent objects (shaded in $\left.\%\right)$ at $t_{0}$, and outflow objects ( $>15 \%$ stippled in black) at $t_{0}+24 \mathrm{~h}$. (f) Relative frequency anomalies of TME objects (shaded in $\%$ ) for $t_{0}-24$ to $t_{0}+12 \mathrm{~h}$. In (a)-(f), only anomaly values that are statistically significant at the $95 \%$ confidence level are plotted. The plus symbol marks the centroid of the central U.S. domain.

region on the southern and western flanks of the surface high and the eastern flank of the surface low (Fig. 9b). The large meridional extent of the IVT corridor favors exports of moist air from the tropics, as manifested by large positive relative frequency anomalies of TME objects (Fig. 9f) overlapping the corridor. The IVT configuration in Fig. 9d closely resembles that documented in previous studies of central U.S. EPEs (e.g., Moore et al. 2012, 2015). The IVT corridor in the eastern U.S. composite (Fig. 10d) extends along the eastern U.S. coast, exhibits a shorter meridional extent than that in the central U.S. composite (Fig. 9d), and is, accordingly, associated with smaller TME relative frequency anomalies (Fig. 10f) than that in the central U.S. composite (Fig. 9f). 
(a)
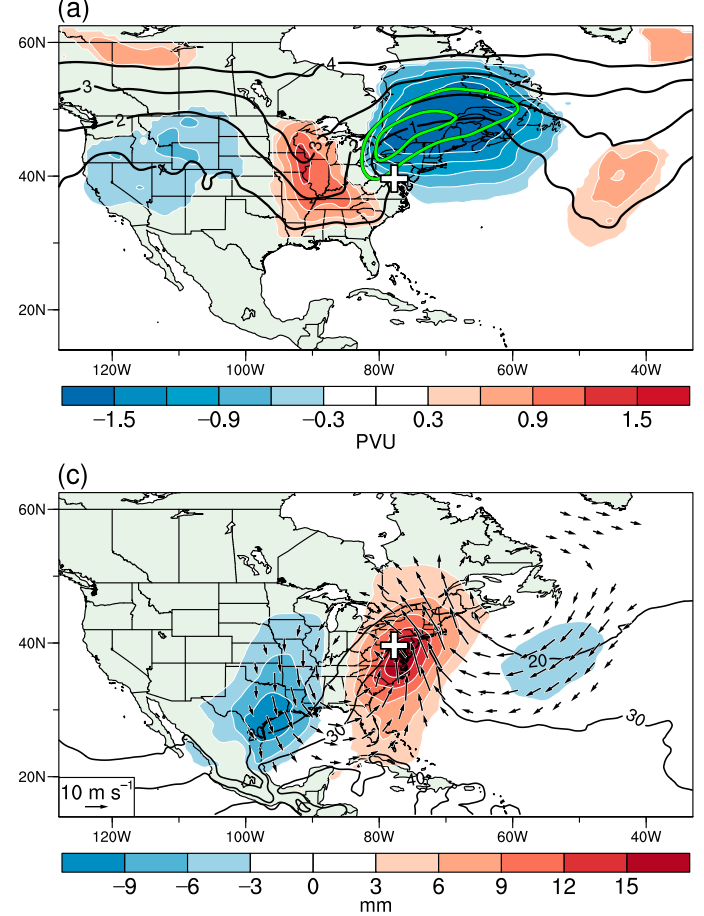

(e)

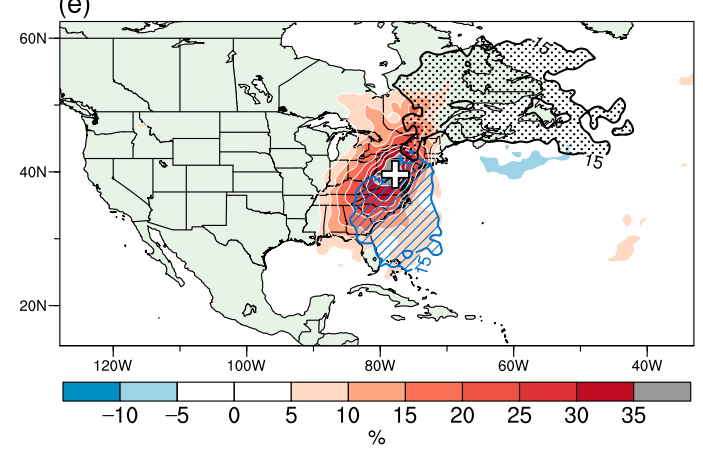

(b)

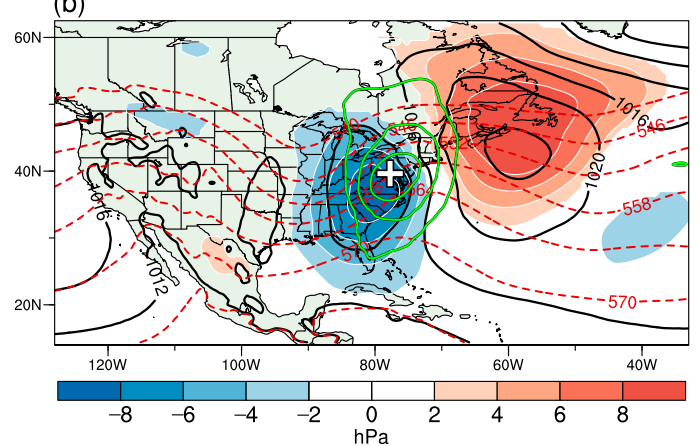

(d)
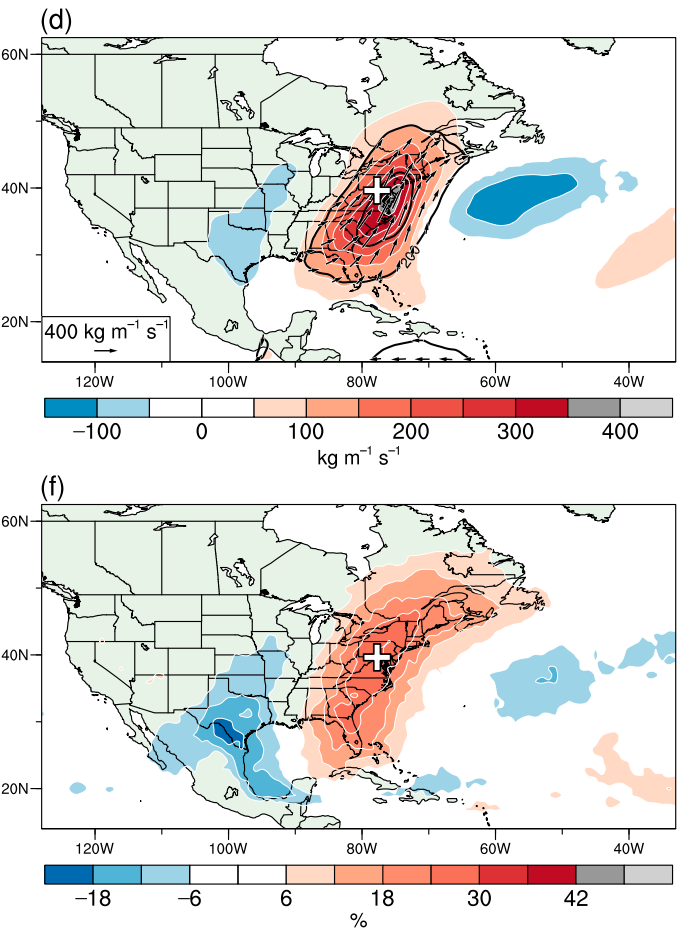

FIG. 10. As in Fig. 9, but for the eastern U.S. widespread EPEs that co-occurred with Rossby wave breaking $(N=74)$.

Hovmöller diagrams of composite $250-\mathrm{hPa}$ meridional wind anomalies (Figs. 11a,c) demonstrate that the synoptic-scale pattern over North America for the two sets of EPEs is established as part of a large-scale Rossby wave packet originating far upstream over the North Pacific $\sim 4-6$ days prior to $t_{0}$. In both composites, the wave packet persists across the eastern North Pacific and North America between about $t_{0}-4$ days and $t_{0}+2$ days (Figs. 11a,c). Between $t_{0}-2$ days and $t_{0}+2$ days, a persistent trough, identifiable as a negative-positive meridional wind anomaly dipole, coincides with anomalously high PV streamer frequencies immediately upstream of each EPE domain (Figs. 11a,c). Concurrently, anomalously strong IVT is established and maintained in each EPE domain (Figs. 11b,d). This configuration illustrates a dynamical link between sustained anomalous water vapor transport into the EPE regions and Rossby wave breaking.

\section{b. Comparison of $A W B$ and $C W B$ cases}

For brevity, analyses of EPEs linked to AWB and CWB are presented only for the central United States. The results for the eastern United States (not shown) are qualitatively similar to those discussed here. The upperlevel flow patterns for the AWB (Fig. 12a) and CWB (Fig. 12b) cases are characterized, respectively, by a positively and negatively tilted trough upstream of the EPE domain. The trough in the CWB composite (Fig. 12b) exhibits larger PV and PV anomaly values than that in the AWB composite (Fig. 12a). Moreover, relative to the AWB composite (Figs. 12c and 13a), the CWB composite (Figs. 12d and 13b) features a stronger and more 

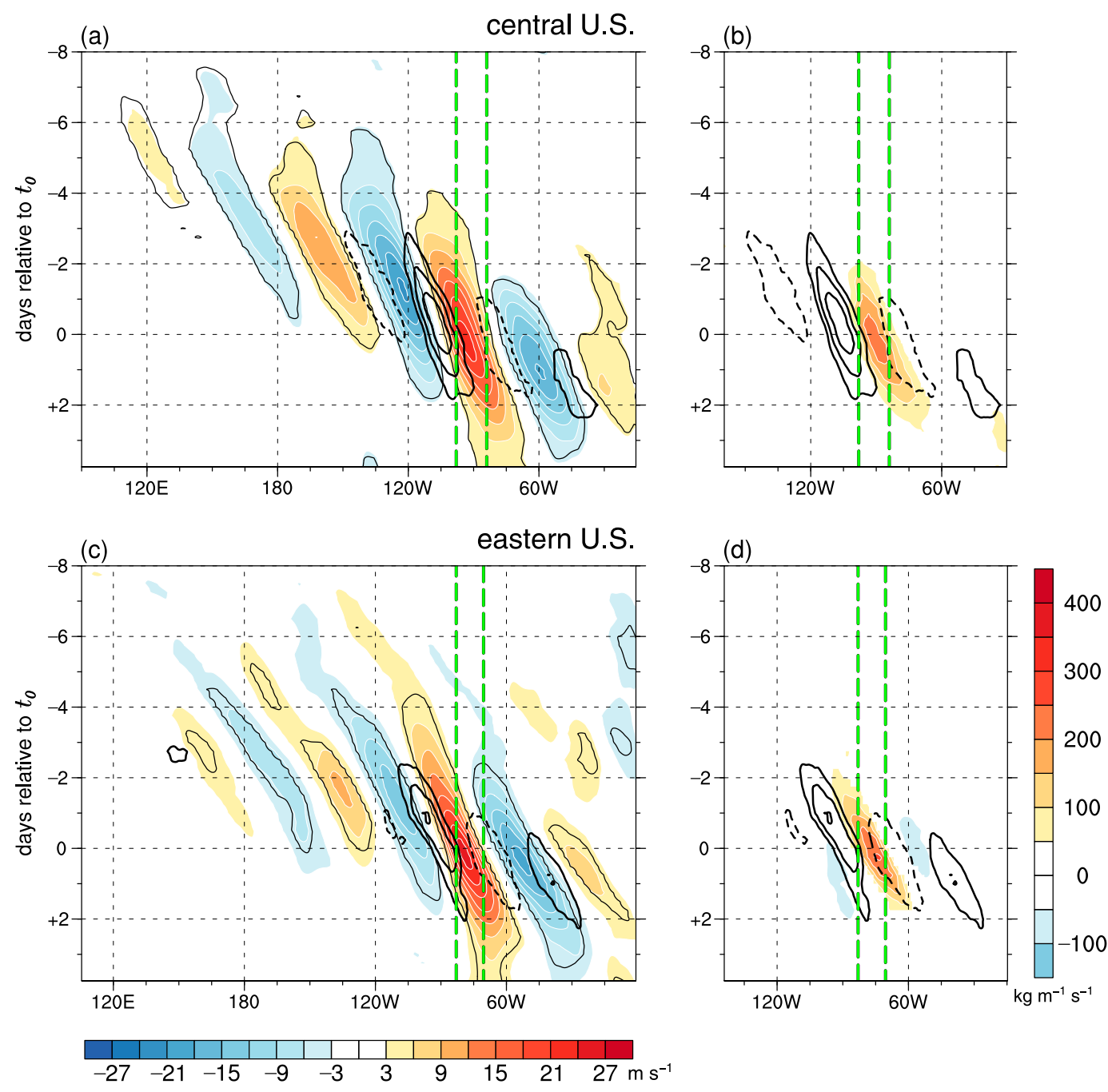

FIG. 11. Composite Hovmöller diagrams for the (a),(b) central $(N=144)$ and (c), (d) eastern $(N=74)$ U.S. widespread EPEs that co-occurred with Rossby wave breaking. (left) 250-hPa meridional wind anomaly (shaded in $\mathrm{m} \mathrm{s}^{-1}$; statistically significant areas at the $95 \%$ confidence level outlined by thin black contours) and relative frequency anomaly of any type of PV streamer (thick black contours every $5 \%$, dashed for negative values; only values statistically significant at the $95 \%$ confidence level plotted) averaged for (a) $30^{\circ}-50^{\circ} \mathrm{N}$ and (c) $35^{\circ}-55^{\circ} \mathrm{N}$. (right) IVT magnitude anomaly (shaded in $\mathrm{kg} \mathrm{m}^{-1} \mathrm{~s}^{-1}$; only values statistically significant at the $95 \%$ confidence level plotted) averaged for (b) $25^{\circ}-40^{\circ} \mathrm{N}$ and (d) $30^{\circ}-45^{\circ} \mathrm{N}$ overlaid by streamer frequency anomalies as in (a),(c), respectively. Dashed green lines mark the longitudinal bounds of the EPE domains.

meridionally elongated surface low associated with stronger $700-\mathrm{hPa}$ cyclonic geostrophic relative vorticity and upward $\omega_{\mathrm{QG}}$ downstream of the trough. The total column water vapor, IVT, and TME patterns are similar between the two composites (not shown).

The QG ascent in both composites (Figs. 13a-f) occurs along a baroclinic zone and includes contributions from $\omega_{n}$ and $\omega_{s}$, with the latter component dominating. The $\omega_{n}$, resulting from frontogenetical forcing, is similar between the two composites (Figs. 13c,d), but the $\omega_{s}$, resulting from rotation of the potential temperature gradient, is stronger in the CWB composite (Figs. 13e,f). The difference in the mean spatially averaged $\omega_{\mathrm{OG}}$ and $\omega_{s}$ in the EPE domain between the CWB and AWB cases is statistically significant at the $95 \%$ level (not shown). In both composites (Figs. 13e,f), $\mathbf{Q}_{\mathbf{s}}$ vectors are directed northeastward along the baroclinic zone (i.e., positive $\mathbf{s}$ direction) into the region of ascent, indicating counterclockwise rotation of the potential temperature gradient. These $\mathbf{Q}_{\mathbf{s}}$ vectors are larger in magnitude and exhibit stronger convergence (not shown) in the CWB composite (Fig. 13f) compared with the AWB 


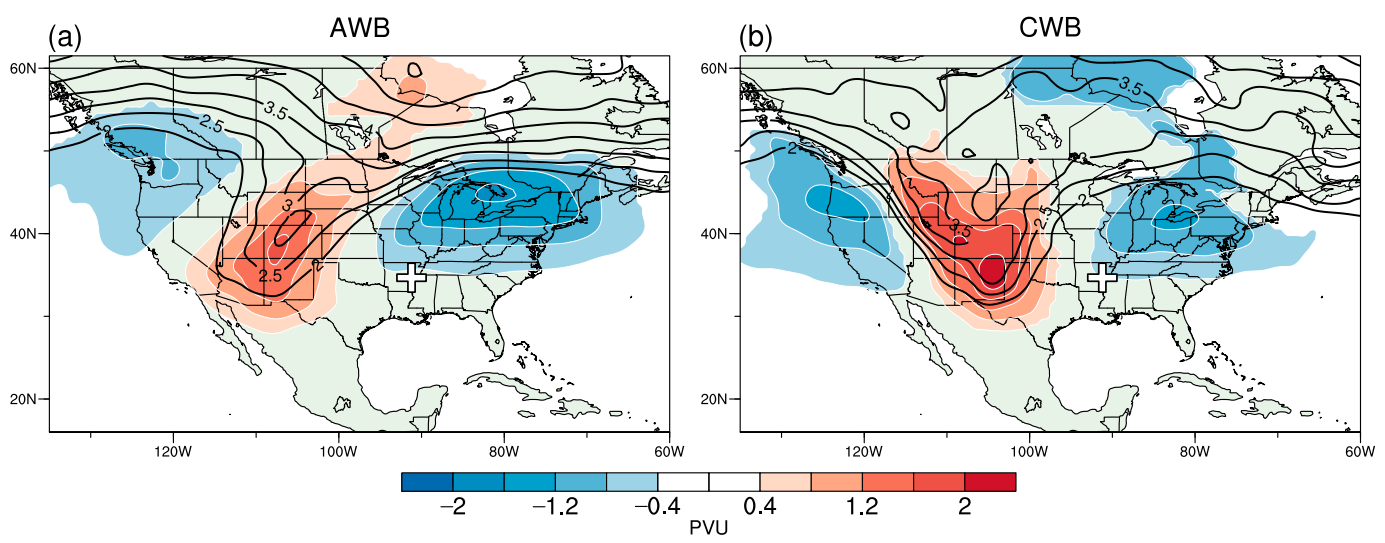

(c)

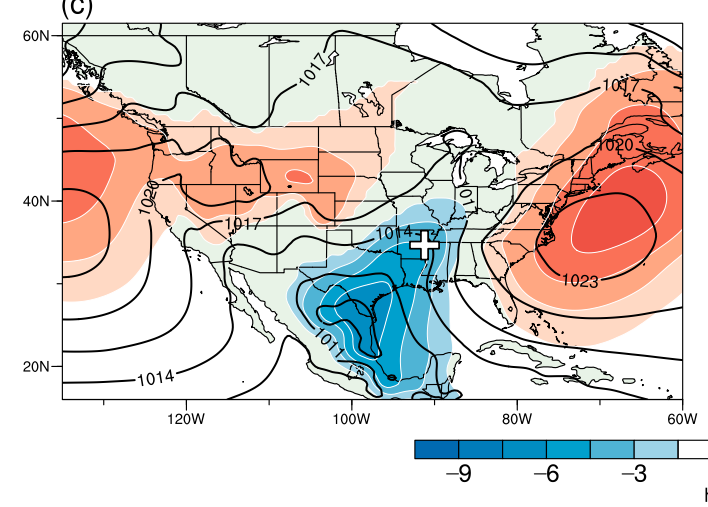

(d)

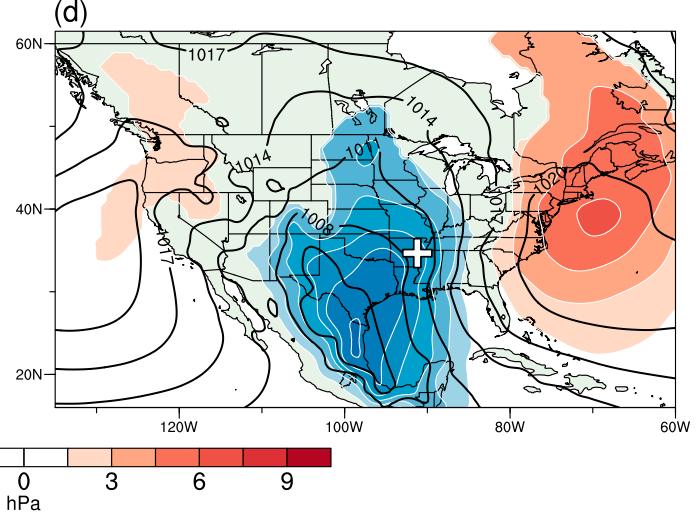

FIG. 12. Composite analyses at $t_{0}$ for widespread EPEs in the central United States that co-occurred with (left) AWB $(N=84)$ and (right) CWB $(N=34)$. (a),(b) 320-K PV (black contours every 0.5 PVU starting at 2 PVU) and PV anomaly (shaded in PVU). (c),(d) Sea level pressure (black contours every $3 \mathrm{hPa}$ ) and sea level pressure anomaly (shaded in $\mathrm{hPa}$ ). In (a)-(d), only anomaly values that are statistically significant at the $95 \%$ confidence level are plotted. The plus symbol marks the centroid of the central U.S. domain.

composite (Fig. 13e), implying stronger forcing of $\omega_{s}$ for the CWB cases. This stronger forcing of $\omega_{s}$ is favored by stronger cyclonic geostrophic vorticity along the baroclinic zone in the CWB composite (Fig. 13b) compared with the AWB composite (Fig. 13a).

\section{Factors distinguishing Rossby wave breaking cases resulting in widespread EPEs}

Given that only a small fraction of wave breaking cases actually result in widespread EPEs (see Table 1), it is of interest from both forecasting and scientific perspectives to identify factors distinguishing such cases from other wave breaking cases. Herein, widespread EPEs co-occurring with a PV streamer are compared in a composite framework with a control sample of null cases, defined as EPEs co-occurring with a streamer that exhibited a precipitation volume in the bottom quartile of the climatological distribution. Differences in the mean between the two samples were tested for statistical significance using a 1000-iteration bootstrap test. For brevity, results are presented only for AWB cases for the central U.S. domain (Fig. 14). The composite results are qualitatively similar between the different Rossby wave breaking types and the two domains (not shown). The samples compared in Fig. 14 comprised 84 and 205 cases, respectively.

The widespread EPE cases are characterized by a higher-amplitude and more-meridional wave pattern over North America than the null cases, as indicated by large 320-K PV differences within a deep trough and a downstream ridge (Fig. 14a) and by large 250-hPa meridional wind differences persisting between $t_{0}-4$ days and $t_{0}+2$ days (Fig. 14c). The wave pattern for the widespread EPE cases is established in connection with a significantly higher-amplitude and longer-lived Rossby wave packet signal than that for the null cases (Fig. 14c). Within the wave pattern, significantly stronger upward $\omega_{\mathrm{QG}}$ (Fig. 14a) and poleward IVT are forced downstream of the trough across the EPE region (Fig. 14b) for the widespread EPE cases than for the null cases. Consistent with an abundant supply of moist air, the 

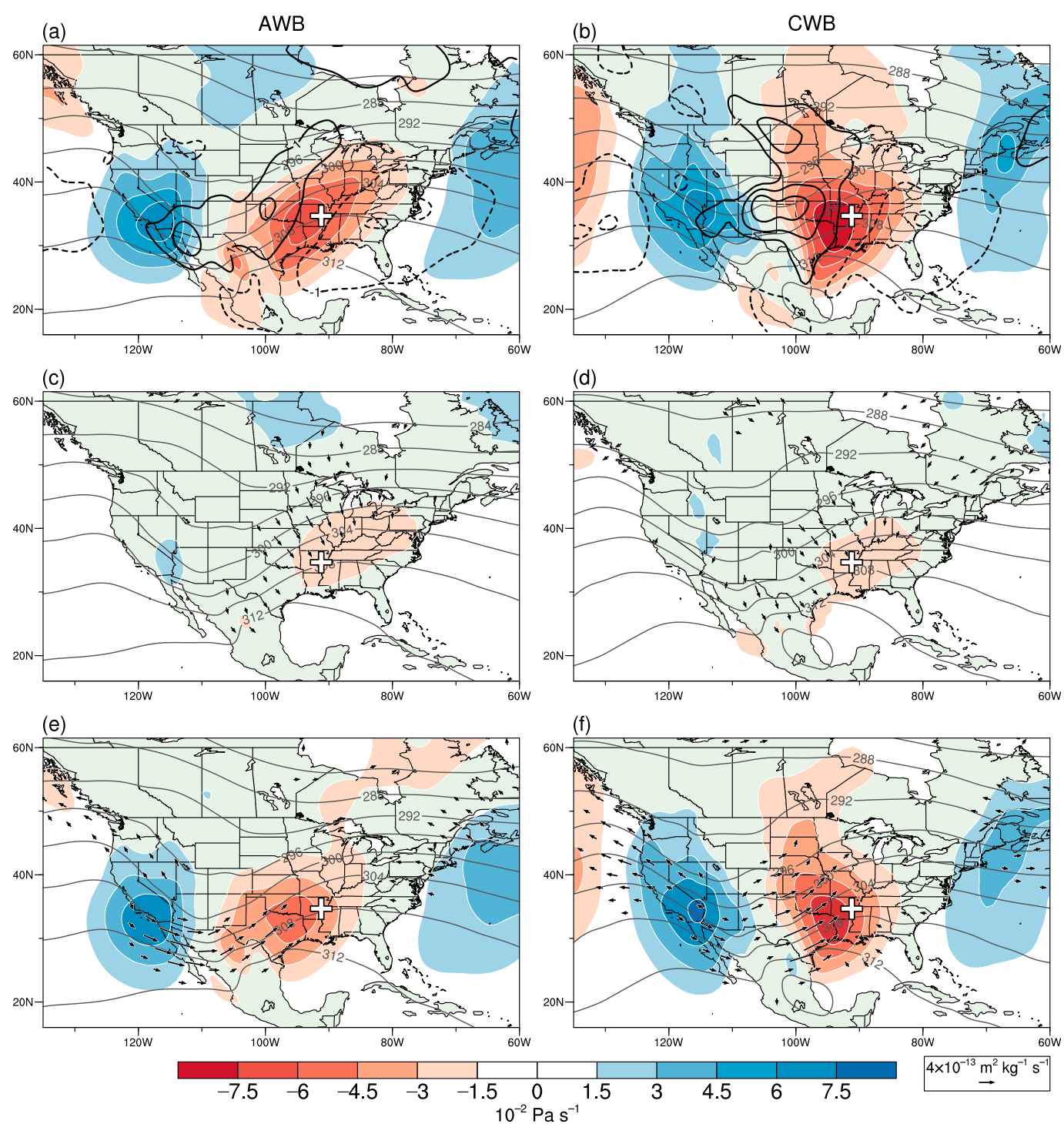

FIG. 13. 700-hPa composite analyses at $t_{0}$ for widespread EPEs in the central United States associated with (left) AWB $(N=84)$ and (right) CWB $(N=34)$. (a),(b) $\omega_{\mathrm{QG}}$ (shaded in $\mathrm{Pa} \mathrm{s}^{-1}$ ), geostrophic relative vorticity (black contours every $10^{-5} \mathrm{~s}^{-1}$; dashed for negative values), and potential temperature (gray contours every $4 \mathrm{~K}$ ). (c),(d) $\omega_{n}$ (shaded in $\mathrm{Pa} \mathrm{s}^{-1}$ ), $\mathbf{Q}_{\mathbf{n}}$ (vector scale in lower right), and potential temperature (gray contours every $4 \mathrm{~K}$ ). (e),(f) $\omega_{s}$ (shaded in $\mathrm{Pa} \mathrm{s}^{-1}$ ), $\mathbf{Q}_{\mathbf{s}}$ (vector scale in lower right), and potential temperature (gray contours every $4 \mathrm{~K}$ ). The plus symbol marks the centroid of the central U.S. domain.

widespread EPE cases tend to involve significantly greater convective available potential energy than the null cases over the EPE region (Fig. 14b), favoring stronger ascent and higher precipitation rates for the widespread EPE cases.

\section{Summary and discussion}

The current study has explored the hypothesis that Rossby wave breaking represents a principal dynamical pathway for the occurrence of EPEs in the central and eastern United States. This hypothesis was addressed through a systematic investigation employing climatologies of EPEs and PV streamers, proxies for Rossby wave breaking, for 1979-2015. The investigation comprised statistical and composite analyses. Widespread EPEs, defined as events exhibiting exceptionally large precipitation volumes, were emphasized. To our knowledge, the current study is the first to quantify linkages between EPEs in the central and eastern United States and Rossby wave breaking.

The findings of the statistical analysis support the hypothesis and are summarized below. 
(a)

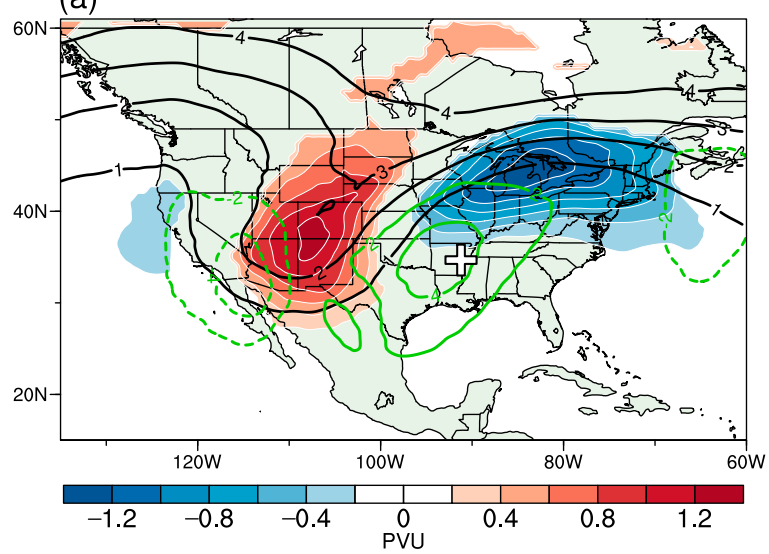

(b)

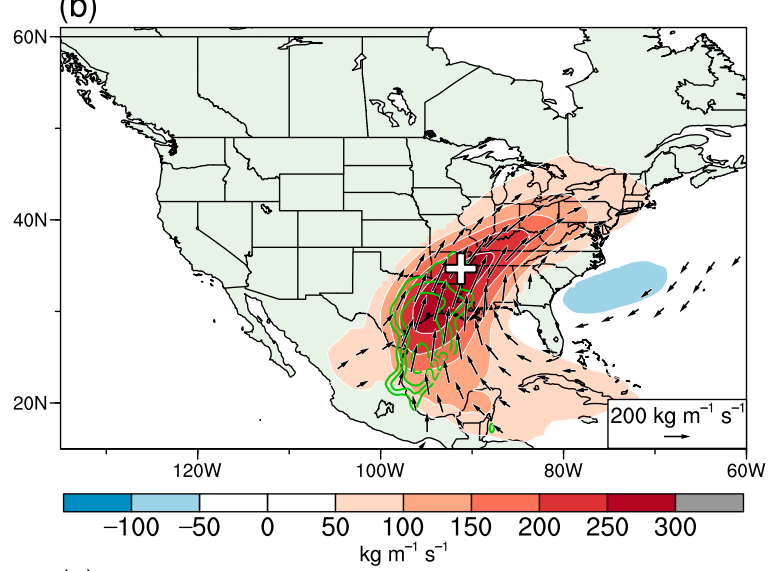

(c)

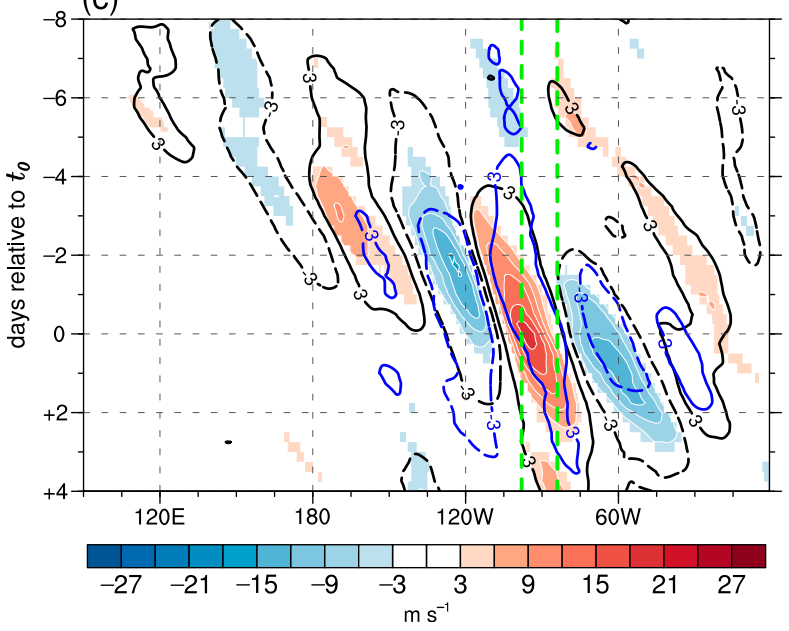

FIG. 14. Composite comparison of widespread EPE $(N=84)$ and null $(N=205)$ AWB cases for the central United States. (a) $320-\mathrm{K}$ PV for the widespread EPE cases (black contours every 1 PVU) and widespread EPE minus null differences of the 320-K PV anomaly (shaded in PVU) and $700-\mathrm{hPa} \omega_{\mathrm{QG}}$ (green contours every $0.02 \mathrm{~Pa} \mathrm{~s}^{-1}$, dashed for positive values) averaged for $t_{0}-12$ to $t_{0}+$ $12 \mathrm{~h}$. (b) Widespread EPE minus null differences of IVT magnitude (shaded in $\mathrm{kg} \mathrm{m}^{-1} \mathrm{~s}^{-1}$ ) and vectors and of surface-based convective available potential energy (green contours every $75 \mathrm{~J} \mathrm{~kg}^{-1}$, positive values only). (c) Hovmöller diagram for $30^{\circ}-50^{\circ} \mathrm{N}$ of widespread
- The conditional relative frequency of PV streamers for widespread EPEs in the central and eastern U.S. domains is significantly enhanced relative to climatology upstream of each domain, indicating a tendency for the EPEs to occur in conjunction with Rossby wave breaking. Accordingly, majorities of the widespread EPEs in the central $(\sim 79 \%)$ and eastern $(\sim 56 \%)$ United States co-occur with a streamer positioned upstream, in qualitative agreement with the findings of prior studies for other regions (Martius et al. 2006; de Vries et al. 2018). The lower co-occurrence fraction for the eastern U.S. EPEs relates to a greater tendency for those EPEs to occur in conjunction with TCs compared to central U.S. EPEs, as found in prior studies (e.g., Kunkel et al. 2012).

- Odds ratios of EPEs for days when a PV streamer occurs upstream of the central and eastern U.S. domains demonstrate a strong, significant statistical association between EPEs and Rossby wave breaking. The odds ratios are well in excess of unity, indicating that the likelihood of an EPE occurring is significantly increased when Rossby wave breaking occurs compared to "ordinary" conditions in the absence of wave breaking. Martius et al. (2006, their Fig. 7a) presented a similar finding for the south side of the European Alps.

- All PV streamer types co-occur and are statistically associated with EPEs in the central and eastern United States. This finding underscores the relevance of all forms of wave breaking to EPEs. For both domains, AWB streamers occur more frequently upstream and account for a larger fraction of EPEs compared to CWB and neutral streamers. For the central United States, the odds ratios indicate a stronger statistical association with widespread EPEs for AWB streamers than for CWB streamers. For the eastern United States, the odds ratios indicate the opposite. For both domains, the odds ratios are considerably larger for neutral streamers than for AWB and CWB streamers. This finding indicates that neutral streamers are especially favorable for EPEs and is consistent with a particularly strong tendency for these streamers to promote strong moist poleward flow.

EPE minus null differences of 250-hPa meridional wind anomalies (shaded in $\mathrm{m} \mathrm{s}^{-1}$ ) overlaid by meridional wind anomalies $(-3$ and $3 \mathrm{~m} \mathrm{~s}^{-1}$ contours, dashed for negative values) for the widespread EPE (black) and null (blue) cases. In (a)-(c), only differences that are statistically significant at the $95 \%$ confidence level are plotted. The plus symbol in (a),(b) marks the centroid of the central U.S. domain. Dashed green lines in (c) mark the longitudinal bounds of the central U.S. domain. 
- The strength of the EPE-Rossby wave breaking relationship tends to increase with increasing EPE precipitation volume, such that widespread EPEs exhibit the largest co-occurrence fractions and odds ratios.

Composite analyses reveal a dynamical role for Rossby wave breaking in the occurrence of widespread EPEs in the central and eastern United States. The EPEs linked to wave breaking occur within persistent high-amplitude synoptic-scale wave patterns over North America, featuring an elongated upper-level trough, or PV streamer, upstream of the EPE region. Prior studies (e.g., Screen and Simmonds 2014; Röthlisberger et al. 2016) have documented statistical links between highamplitude Rossby wave patterns and regional precipitation extremes; the composite analyses herein suggest that Rossby wave breaking can be a key dynamical process for establishing such links. As found previously for wave breaking-related EPEs (e.g., Martius et al. 2008; Bosart et al. 2017), the wave pattern is established in connection with a long-lived Rossby wave packet originating far upstream. Investigation of the processes governing the initiation and evolution of wave packets culminating in wave breaking-related EPEs-and the implications of these packets for medium-range predictability (e.g., Grazzini and Vitart 2015)—would be a highly valuable avenue for future research.

Anomalous poleward lower-tropospheric flow downstream of the upper-level trough is linked to sustained water vapor transport into the EPE region within a meridionally elongated corridor resembling an atmospheric river. The large meridional extent of the corridor favors transport of moist air from the tropics, as documented in prior case studies (e.g., Moore et al. 2012; Bosart et al. 2017). Upward $\omega_{\mathrm{QG}}$ occurs in the EPE region in association with WCB activity where the moist poleward flow encounters a baroclinic zone. The ascent in the EPE region is forced in association with both frontogenesis $\left(\omega_{n}\right)$ and rotation of the potential temperature gradient $\left(\omega_{s}\right)$ along the baroclinic zone. The EPEs associated with CWB are characterized by significantly stronger $\omega_{s}$ than those associated with AWB. This finding relates to a tendency for the CWB cases to exhibit a greater counterclockwise rotation of the potential temperature gradient along the baroclinic zone in association with stronger lower-tropospheric cyclonic vorticity than the AWB cases. Given marked differences in cyclogenesis and the concomitant thermal wave evolution between AWB- and CWB-related baroclinic life cycles (see Davies et al. 1991, their Figs. 8 and 9), the partitioning of vertical motion into components due to cross- and along-isentropic forcing constitutes an instructive framework for characterizing and distinguishing the dynamics of AWB and CWB scenarios.

Only a small fraction of wave breaking cases in which a PV streamer is positioned upstream of a given domain actually result in a widespread EPE in that domain. Thus, Rossby wave breaking should be regarded as a favorable but not sufficient condition for the occurrence of widespread EPEs. Additional composite analyses reveal that Rossby wave breaking cases linked to widespread EPEs tend to exhibit a considerably higher-amplitude wave pattern over North America than corresponding null wave breaking cases. This wave pattern in turn promotes significantly stronger poleward transport of moist, conditionally unstable air and stronger ascent, favoring widespread extreme precipitation.

A limitation of the current study is its restriction to two particular regions of the United States. Thus, the linkage between EPEs and Rossby wave breaking elsewhere in the world remains unclear. A worthwhile future research endeavor could be to expand the analysis of the EPE-Rossby wave breaking linkage to a global framework. An additional limitation of the current study is that the dynamical processes by which Rossby wave breaking may result in EPEs were only briefly examined. Detailed multiscale composite analyses and case studies are needed to further identify and diagnose these processes. As a complement to this research, evaluation of the representation of Rossby wave breaking and associated precipitation events in medium- and extended-range numerical model forecasts could identify systematic forecast errors and thereby help to guide future model improvements.

Acknowledgments. This research was performed as part of the first author's Ph.D. dissertation at the University at Albany, SUNY, with support from National Science Foundation Grants AGS-1355960 and AGS-1656406. Special thanks go to Michael Sprenger and Heini Wernli at ETH-Zurich for generously providing the TME and WCB climatologies, and to Philippe Papin (NRL) for help coding the PV streamer algorithm. Thanks also to the anonymous peer reviewers for their helpful comments. The NCAR Command Language version 6.5.0 was used for data processing, analysis, and visualization.

\section{REFERENCES}

Appenzeller, C., and H. C. Davies, 1992: Structure of stratospheric intrusions into the troposphere. Nature, 358, 570-572, https:// doi.org/10.1038/358570a0.

Ashley, S. T., and W. S. Ashley, 2008: Flood fatalities in the United States. J. Appl. Meteor. Climatol., 47, 805-818, https://doi.org/ 10.1175/2007JAMC1611.1. 
Bosart, L. F., B. J. Moore, J. M. Cordeira, and H. M. Archambault, 2017: Interactions of North Pacific tropical, midlatitude, and polar disturbances resulting in linked extreme weather events over North America in October 2007. Mon. Wea. Rev., 145, 1245-1273, https://doi.org/10.1175/ MWR-D-16-0230.1.

Brooks, H. E., and D. J. Stensrud, 2000: Climatology of heavy rain events in the United States from hourly precipitation observations. Mon. Wea. Rev., 128, 1194-1201, https://doi.org/10.1175/ 1520-0493(2000)128<1194:COHREI > 2.0.CO;2.

Browning, K. A., 1986: Conceptual models of precipitation systems. Wea. Forecasting, 1, 23-41, https://doi.org/10.1175/ 1520-0434(1986)001<0023:CMOPS > 2.0.CO;2.

_ 1990 : Organization of clouds and precipitation in extratropical cyclones. Extratropical Cyclones: The Erik Palmén Memorial Volume, C. W. Newton and E. O. Holopainen, Eds., Amer. Meteor. Soc., 129-153.

—, and C. W. Pardoe, 1973: Structure of low-level jet streams ahead of mid-latitude cold fronts. Quart. J. Roy. Meteor. Soc., 99, 619-638, https://doi.org/10.1002/qj.49709942204.

Carlson, T. N., 1980: Airflow through midlatitude cyclones and the comma cloud pattern. Mon. Wea. Rev., 108, 1498-1509, https:// doi.org/10.1175/1520-0493(1980)108<1498:ATMCAT>2.0.CO;2.

Catto, J. L., and S. Pfahl, 2013: The importance of fronts for extreme precipitation. J. Geophys. Res., 118, 10 791-10 801, https://doi.org/ 10.1002 /jgrd.50852.

Davies, H. C., C. Schär, and H. Wernli, 1991: The palette of fronts and cyclones within a baroclinic wave development. J. Atmos. Sci., $\mathbf{4 8}$, 1666-1689, https://doi.org/10.1175/1520-0469(1991)048<1666: TPOFAC $>2.0 . \mathrm{CO} ; 2$.

de Vries, A. J., H. G. Ouwersloot, S. B. Feldstein, M. Riemer, A. M. E. Kenawy, M. F. McCabe, and J. Lelieveld, 2018: Identification of tropical-extratropical interactions and extreme precipitation events in the Middle East based on potential vorticity and moisture transport. J. Geophys. Res., 123, 861-881, https://doi.org/10.1002/2017JD027587.

Dee, D. P., and Coauthors, 2011: The ERA-Interim reanalysis: Configuration and performance of the data assimilation system. Quart. J. Roy. Meteor. Soc., 137, 553-597, https://doi.org/ 10.1002/qj.828.

Doswell, C. A., H. E. Brooks, and R. A. Maddox, 1996: Flash flood forecasting: An ingredients-based methodology. Wea. Forecasting, 11, 560-581, https://doi.org/10.1175/1520-0434(1996) $011<0560$ :FFFAIB $>2.0$.CO;2.

ECMWF, 2009: ERA-Interim Project (updated monthly). NCAR Computational and Information Systems Laboratory Research Data Archive, accessed 27 March 2018, https://oi.org/ 10.5065/D6CR5RD9.

Gochis, D., and Coauthors, 2015: The Great Colorado Flood of September 2013. Bull. Amer. Meteor. Soc., 96, 1461-1487, https://doi.org/10.1175/BAMS-D-13-00241.1.

Grams, C. M., H. Binder, S. Pfahl, N. Piaget, and H. Wernli, 2014: Atmospheric processes triggering the central European floods in June 2013. Nat. Hazards Earth Syst. Sci., 14, 1691-1702, https://doi.org/10.5194/nhess-14-1691-2014.

Grazzini, F., and F. Vitart, 2015: Atmospheric predictability and Rossby wave packets. Quart. J. Roy. Meteor. Soc., 141, 2793-2802, https://doi.org/10.1002/qj.2564.

Harrold, T. W., 1973: Mechanisms influencing the distribution of precipitation within baroclinic disturbances. Quart. J. Roy. Meteor. Soc., 99, 232-251, https://doi.org/10.1002/qj.49709942003.

Higgins, R. W., W. Shi, E. Yarosh, and R. Joyce, 2000: Improved United States Precipitation Quality Control System and Analysis. NCEP/Climate Prediction Center Atlas 7, 40 pp.
Hitchens, N. M., M. E. Baldwin, and R. J. Trapp, 2012: An object-oriented characterization of extreme precipitationproducing convective systems in the Midwestern United States. Mon. Wea. Rev., 140,1356-1366, https://doi.org/10.1175/ MWR-D-11-00153.1.

Holton, J. R., and G. J. Hakim, 2013: An Introduction to Dynamic Meteorology. Elsevier Academic Press, 532 pp.

Hoskins, B. J., I. Draghici, and H. C. Davies, 1978: A new look at the $\omega$-equation. Quart. J. Roy. Meteor. Soc., 104, 31-38, https:// doi.org/10.1002/qj.49710443903.

Houze, R. A., K. L. Rasmussen, S. Medina, S. R. Brodzik, and U. Romatschke, 2011: Anomalous atmospheric events leading to the summer 2010 floods in Pakistan. Bull. Amer. Meteor. Soc., 92, 291-298, https://doi.org/10.1175/2010BAMS3173.1.

Hu, H., F. Dominguez, Z. Wang, D. A. Lavers, G. Zhang, and F. M. Ralph, 2017: Linking atmospheric river hydrological impacts on the U.S. West Coast to Rossby wave breaking. J. Climate, 30, 3381-3399, https://doi.org/10.1175/JCLI-D-16-0386.1.

Jongman, B., P. J. Ward, and J. C. J. H. Aerts, 2012: Global exposure to river and coastal flooding: Long term trends and changes. Global Environ. Change, 22, 823-835, https://doi.org/ 10.1016/j.gloenvcha.2012.07.004.

Keyser, D., M. J. Reeder, and R. J. Reed, 1988: A generalization of Petterssen's frontogenesis function and its relation to the forcing of vertical motion. Mon. Wea. Rev., 116, 762-781, https://doi.org/ 10.1175/1520-0493(1988)116<0762:AGOPFF > 2.0.CO;2.

, B. D. Schmidt, and D. G. Duffy, 1992: Quasigeostrophic vertical motions diagnosed from along- and cross-isentrope components of the Q vector. Mon. Wea. Rev., 120, 731-741, https://doi.org/ 10.1175/1520-0493(1992)120<0731:QVMDFA>2.0.CO;2.

Knapp, K. R., M. C. Kruk, D. H. Levinson, H. J. Diamond, and C. J. Neumann, 2010: The International Best Track Archive for Climate Stewardship (IBTrACS). Bull. Amer. Meteor. Soc., 91, 363-376, https://doi.org/10.1175/2009BAMS2755.1.

Knippertz, P., and J. E. Martin, 2007a: The role of dynamic and diabatic processes in the generation of cut-off lows over Northwest Africa. Meteor. Atmos. Phys., 96, 3-19, https://doi.org/10.1007/ s00703-006-0217-4.

$\longrightarrow$, and - 2007b: A Pacific moisture conveyor belt and its relationship to a significant precipitation event in the semiarid southwestern United States. Wea. Forecasting, 22, 125-144, https://doi.org/10.1175/WAF963.1.

_ , and H. Wernli, 2010: A Lagrangian climatology of tropical moisture exports to the Northern Hemispheric extratropics. J. Climate, 23, 987-1003, https://doi.org/10.1175/2009JCLI3333.1.

Konrad, C. E., 2001: The most extreme precipitation events over the eastern United States from 1950 to 1996: Considerations of scale. J. Hydrometeor., 2, 309-325, https://doi.org/10.1175/ 1525-7541(2001)002<0309:TMEPEO > 2.0.CO;2.

Kunkel, K. E., D. R. Easterling, D. A. R. Kristovich, B. Gleason, L. Stoecker, and R. Smith, 2012: Meteorological causes of the secular variations in observed extreme precipitation events for the conterminous United States. J. Hydrometeor., 13, 11311141, https://doi.org/10.1175/JHM-D-11-0108.1.

Larson, J., Y. Zhou, and R. W. Higgins, 2005: Characteristics of landfalling tropical cyclones in the United States and Mexico: Climatology and interannual variability. J. Climate, 18, 12471262, https://doi.org/10.1175/JCLI3317.1.

Lenggenhager, S., and O. Martius, 2019: Atmospheric blocks modulate the odds of heavy precipitation events in Europe. Climate Dyn., in press, https://doi.org/10.1007/s00382-019-04779-0.

-, M. Croci-Maspoli, S. Brönnimann, and O. Martius, 2019: On the dynamical coupling between atmospheric blocks and heavy 
precipitation events: A discussion of the southern Alpine flood in October 2000. Quart. J. Roy. Meteor. Soc., 145, 530-545, https:// doi.org/10.1002/qj.3449.

Maddox, R. A., C. F. Chappell, and L. R. Hoxit, 1979: Synoptic and meso- $\alpha$ scale aspects of flash flood events. Bull. Amer. Meteor. Soc., 60, 115-123, https://doi.org/10.1175/1520-0477-60.2.115.

Madonna, E., H. Wernli, H. Joos, and O. Martius, 2014: Warm conveyor belts in the ERA-Interim dataset (1979-2010). Part I: Climatology and potential vorticity evolution. J. Climate, 27, 3-26, https://doi.org/10.1175/JCLI-D-12-00720.1.

Martin, J. E., 2006: The role of shearwise and transverse quasigeostrophic vertical motions in the midlatitude cyclone life cycle. Mon. Wea. Rev., 134, 1174-1193, https://doi.org/10.1175/ MWR3114.1.

Martius, O., E. Zenklusen, C. Schwierz, and H. C. Davies, 2006: Episodes of Alpine heavy precipitation with an overlying elongated stratospheric intrusion: A climatology. Int. J. Climatol., 26, 1149-1164, https://doi.org/10.1002/joc.1295.

— C. Schwierz, and H. C. Davies, 2007: Breaking waves at the tropopause in the wintertime Northern Hemisphere: Climatological analyses of the orientation and the theoretical $\mathrm{LC} 1 / 2$ classification. J. Atmos. Sci., 64, 2576-2592, https://doi.org/ 10.1175/JAS3977.1.

,-- , and,- 2008: Far-upstream precursors of heavy precipitation events on the Alpine south-side. Quart. J. Roy. Meteor. Soc., 134, 417-428, https://doi.org/10.1002/qj.229.

,-- , and 2010: Tropopause-level waveguides. J. Atmos. Sci., 67, 866-879, https://doi.org/10.1175/2009JAS2995.1.

— face processes for the Pakistan flood of July 2010. Quart. J. Roy. Meteor. Soc., 139, 1780-1797, https://doi.org/10.1002/qj.2082.

Massacand, A. C., H. Wernli, and H. C. Davies, 1998: Heavy precipitation on the Alpine southside: An upper-level precursor. Geophys. Res. Lett., 25, 1435-1438, https://doi.org/10.1029/ 98GL50869.

McIntyre, M. E., and T. N. Palmer, 1983: Breaking planetary waves in the stratosphere. Nature, 305, 593-600, https://doi.org/ $10.1038 / 305593 \mathrm{a} 0$.

— , and - 1984: The "surf zone" in the stratosphere. J. Atmos. Terr. Phys., 46, 825-849, https://doi.org/10.1016/0021-9169(84) 90063-1.

Moore, B. J., P. J. Neiman, F. M. Ralph, and F. E. Barthold, 2012: Physical processes associated with heavy flooding rainfall in Nashville, Tennessee, and vicinity during 1-2 May 2010: The role of an atmospheric river and mesoscale convective systems. Mon. Wea. Rev., 140, 358-378, https://doi.org/10.1175/ MWR-D-11-00126.1.

_ , K. M. Mahoney, E. M. Sukovich, R. Cifelli, and T. M. Hamill, 2015: Climatology and environmental characteristics of extreme precipitation events in the southeastern United States. Mon. Wea. Rev., 143, 718-741, https://doi.org/10.1175/MWR-D-14-00065.1.

Neiman, P. J., M. A. Shapiro, and L. S. Fedor, 1993: The life cycle of an extratropical marine cyclone. Part II: Mesoscale structure and diagnostics. Mon. Wea. Rev., 121, 2177-2199, https:/doi.org/ 10.1175/1520-0493(1993)121<2177:TLCOAE > 2.0.CO;2.

, F. M. Ralph, G. A. Wick, J. D. Lundquist, and M. D. Dettinger, 2008: Meteorological characteristics and overland precipitation impacts of atmospheric rivers affecting the west coast of North America based on eight years of SSM/I satellite observations. J. Hydrometeor., 9, 22-47, https://doi.org/10.1175/ 2007JHM855.1.

Newell, R. E., N. E. Newell, Y. Zhu, and C. Scott, 1992: Tropospheric rivers? A pilot study. Geophys. Res. Lett., 19, 24012404, https://doi.org/10.1029/92GL02916.
NOAA/NCEI, 2018a: International Best Track Archive for Climate Stewardship dataset. NOAA/National Centers for Environmental Information, accessed 15 January 2018, https:// www.ncdc.noaa.gov/ibtracs/index.php.

2018b: U.S. billion-dollar weather and climate disasters. NOAA/National Centers for Environmental Information, accessed 10 September 2018, https://www.ncdc.noaa.gov/ billions/.

NOAA/NCEP/CPC, 2018: NOAA/CPC .25 X .25 daily U.S. unified precipitation dataset (updated daily). NOAA/OAR/ESRL/PSD data archive, accessed 15 January 2018, https://www.esrl.noaa.gov/ $\mathrm{psd} /$ data/gridded/data.unified.html.

Payne, A. E., and G. Magnusdottir, 2014: Dynamics of landfalling atmospheric rivers over the North Pacific in 30 years of MERRA reanalysis. J. Climate, 27, 7133-7150, https://doi.org/ 10.1175/JCLI-D-14-00034.1.

Pfahl, S., and H. Wernli, 2012: Quantifying the relevance of cyclones for precipitation extremes. J. Climate, 25, 6770-6780, https://doi.org/10.1175/JCLI-D-11-00705.1.

__, E. Madonna, M. Boettcher, H. Joos, and H. Wernli, 2014: Warm conveyor belts in the ERA-Interim dataset (19792010). Part II: Moisture origin and relevance for precipitation. J. Climate, 27, 27-40, https://doi.org/10.1175/ JCLI-D-13-00223.1.

Prat, O. P., and B. R. Nelson, 2016: On the link between tropical cyclones and daily rainfall extremes derived from global satellite observations. J. Climate, 29, 6127-6135, https://doi.org/ 10.1175/JCLI-D-16-0289.1.

Press, W. H., S. A. Teukolsky, W. T. Vetterling, and B. P. Flannery, 2007: Numerical Recipes: The Art of Scientific Computing. 3rd ed. Cambridge University Press, 1256 pp.

Quinting, J. F., and S. C. Jones, 2016: On the impact of tropical cyclones on Rossby wave packets: A climatological perspective. Mon. Wea. Rev., 144, 2021-2048, https://doi.org/10.1175/ MWR-D-14-00298.1.

Ralph, F. M., P. J. Neiman, and G. A. Wick, 2004: Satellite and CALJET aircraft observations of atmospheric rivers over the eastern North Pacific Ocean during the winter of 1997/98. Mon. Wea. Rev., 132, 1721-1745, https://doi.org/10.1175/15200493(2004)132<1721:SACAOO > 2.0.CO;2.

- — - and R. Rotunno, 2005: Dropsonde observations in low-level jets over the northeastern Pacific Ocean from CALJET-1998 and PACJET-2001: Mean vertical-profile and atmospheric-river characteristics. Mon. Wea. Rev., 133, 889910, https://doi.org/10.1175/MWR2896.1.

Röthlisberger, M., S. Pfahl, and O. Martius, 2016: Regional-scale jet waviness modulates the occurrence of midlatitude weather extremes. Geophys. Res. Lett., 43, 10 989-10 997, https:// doi.org/10.1002/2016GL070944.

_ O. Martius, and H. Wernli, 2018: Northern Hemisphere Rossby wave initiation events on the extratropical jet-A climatological analysis. J. Climate, 31, 743-760, https://doi.org/ 10.1175/JCLI-D-17-0346.1.

Ryoo, J.-M., Y. Kaspi, D. W. Waugh, G. N. Kiladis, D. E. Waliser, E. J. Fetzer, and J. Kim, 2013: Impact of Rossby wave breaking on U.S. West Coast winter precipitation during ENSO events. J. Climate, 26, 6360-6382, https://doi.org/10.1175/JCLI-D-12-00297.1.

_, D. E. Waliser, D. W. Waugh, S. Wong, E. J. Fetzer, and I. Fung, 2015: Classification of atmospheric river events on the U.S. West Coast using a trajectory model. J. Geophys. Res., 120, 3007-3028, https://doi.org/10.1002/2014JD022023.

Saharia, M., P.-E. Kirstetter, H. Vergara, J. J. Gourley, Y. Hong, and M. Giroud, 2017: Mapping flash flood severity in the 
United States. J. Hydrometeor., 18, 397-411, https://doi.org/ 10.1175/JHM-D-16-0082.1.

Schäfler, A., M. Boettcher, C. M. Grams, M. Rautenhaus, H. Sodemann, and H. Wernli, 2014: Planning aircraft measurements within a warm conveyor belt. Weather, 69, 161-166, https://doi.org/10.1002/wea.2245.

Schlemmer, L., O. Martius, M. Sprenger, C. Schwierz, and A. Twitchett, 2010: Disentangling the forcing mechanisms of a heavy precipitation event along the Alpine south side using potential vorticity inversion. Mon. Wea. Rev., 138, 2336-2353, https://doi.org/10.1175/2009MWR3202.1.

Schumacher, R. S., and R. H. Johnson, 2006: Characteristics of U.S extreme rain events during 1999-2003. Wea. Forecasting, 21, 69-85, https://doi.org/10.1175/WAF900.1.

Screen, J. A., and I. Simmonds, 2014: Amplified mid-latitude planetary waves favour particular regional weather extremes. Nat. Climate Change, 4, 704-709, https://doi.org/ 10.1038/nclimate2271.

Smith, W., and R. J. Younkin, 1972: An operationally useful relationship between the polar jet stream and heavy precipitation. Mon. Wea. Rev., 100, 434-440, https://doi.org/10.1175/1520-0493(1972) $100<0434$ :AOURBT $>2.3 . \mathrm{CO} ; 2$

Sodemann, H., and A. Stohl, 2013: Moisture origin and meridional transport in atmospheric rivers and their association with multiple cyclones. Mon. Wea. Rev., 141, 2850-2868, https:// doi.org/10.1175/MWR-D-12-00256.1.

-, H. Wernli, and C. Schwierz, 2009: Sources of water vapour contributing to the Elbe flood in August 2002-A tagging study in a mesoscale model. Quart. J. Roy. Meteor. Soc., $\mathbf{1 3 5}$ 205-223, https://doi.org/10.1002/qj.374.

Špitalar, M., J. J. Gourley, C. Lutoff, P.-E. Kirstetter, M. Brilly, and N. Carr, 2014: Analysis of flash flood parameters and human impacts in the US from 2006 to 2012. J. Hydrol., 519, 863-870, https://doi.org/10.1016/j.jhydrol.2014.07.004.

Sprenger, M., and H. Wernli, 2015: The LAGRANTO Lagrangian analysis tool-version 2.0. Geosci. Model Dev., 8, 2569-2586, https://doi.org/10.5194/gmd-8-2569-2015.
O. Martius, and J. Arnold, 2013: Cold surge episodes over southeastern Brazil-A potential vorticity perspective. Int. J. Climatol., 33, 2758-2767, https://doi.org/10.1002/joc.3618. , and Coauthors, 2017: Global climatologies of Eulerian and Lagrangian flow features based on ERA-Interim. Bull. Amer. Meteor. Soc., 98, 1739-1748, https://doi.org/10.1175/ BAMS-D-15-00299.1.

Thorncroft, C. D., B. J. Hoskins, and M. E. Mcintyre, 1993: Two paradigms of baroclinic-wave life-cycle behaviour. Quart. J. Roy. Meteor. Soc., 119, 17-55, https://doi.org/10.1002/ qj. 49711950903.

UCAR/NCAR/CISL/TDD, 2018: The NCAR Command Language, version 6.5.0. UCAR/NCAR/CISL/TDD, accessed 1 August 2018, https://doi.org/10.5065/D6WD3XH5.

Ulbrich, U., T. Brücher, A. H. Fink, G. C. Leckebusch, A. Krüger, and J. G. Pinto, 2003: The central European floods of August 2002: Part 1-Rainfall periods and flood development. Weather, 58, 371-377, https://doi.org/10.1256/wea.61.03A.

Wernli, H., 1997: A Lagrangian-based analysis of extratropical cyclones. II: A detailed case-study. Quart. J. Roy. Meteor. Soc., 123, 1677-1706, https://doi.org/10.1002/qj.49712354211. and M. Sprenger, 2007: Identification and ERA-15 climatology of potential vorticity streamers and cutoffs near the extratropical tropopause. J. Atmos. Sci., 64, 1569-1586, https:// doi.org/10.1175/JAS3912.1.

White, A. B., B. J. Moore, D. J. Gottas, and P. J. Neiman, 2019: Winter storm conditions leading to excessive runoff above California's Oroville Dam during January and February 2017. Bull. Amer. Meteor. Soc., 100, 55-70, https://doi.org/10.1175/ BAMS-D-18-0091.1.

Wilks, D. S., 2011: Statistical Methods in the Atmospheric Sciences. 3rd ed. International Geophysics Series, Vol. 100, Academic Press, $704 \mathrm{pp}$.

Zhu, Y., and R. E. Newell, 1998: A proposed algorithm for moisture fluxes from atmospheric rivers. Mon. Wea. Rev., 126, 725-735, https://doi.org/10.1175/1520-0493(1998)126<0725: APAFMF $>2.0 . \mathrm{CO} ; 2$ 